\title{
An Exchange Window for the Injection of Antarctic Intermediate Water into the South Pacific
}

\author{
DANIELE IUDiCONE
}

Laboratoire d'Océanographie et du Climat: Expérimentations et Approches Numériques, Unité Mixte de Recherche 7159 CNRS/IRD/UPMC/MNHN, Institut Pierre Simon Laplace, Paris, France, and Stazione Zoologica “Anton Dohrn," Naples, Italy

\section{KeITH B. RODGERS}

Laboratoire d'Océanographie et du Climat: Expérimentations et Approches Numériques, Unité Mixte de Recherche 7159 CNRS/IRD/UPMC/MNHN, Institut Pierre Simon Laplace, Paris, France

\section{RICHARD SCHOPP}

Laboratoire de Physique des Océans, CNRS-IFREMER-UBO, Plouzané, France

\section{GuRVAN MADEC}

Laboratoire d'Océanographie et du Climat: Expérimentations et Approches Numériques, Unité Mixte de Recherche 7159 CNRS/IRD/UPMC/MNHN, Institut Pierre Simon Laplace, Paris, France

(Manuscript received 18 March 2005, in final form 22 February 2006)

\begin{abstract}
Antarctic Intermediate Water (AAIW) occupies the intermediate horizon of most of the world oceans. Formed in the Southern Ocean, it is characterized by a relative salinity minimum. With a new, denser in situ National Oceanographic Data Center dataset, the authors have reanalyzed the export characteristics of AAIW from the Southern Ocean into the South Pacific Ocean. These new data show that part of the AAIW is exported from the subpolar frontal region by the large-scale circulation through an exchange window of $10^{\circ}$ width situated east of $90^{\circ} \mathrm{W}$ in the southeast corner of the Pacific basin. This suggests the origin of this water to be in the Antarctic Circumpolar Current. A set of numerical modeling experiments has been used to reproduce these observed features and to demonstrate that the dynamics of the exchange window is controlled by the basin-scale meridional pressure gradient. The exchange of AAIW between the Southern and Pacific Oceans must therefore be understood in the context of the large basin-scale dynamical balance rather than simply local effects.
\end{abstract}

\section{Introduction}

The Southern Ocean is known to play a key role in the global ocean circulation, as it is the region of exchange between the deep thermohaline circulation and the wind-driven circulation. In particular, the Southern Ocean is a region characterized by large formation rates of both Subantarctic Mode Water (SAMW) and Antarctic Intermediate Water (AAIW) (Hanawa and Talley 2001; Sloyan and Rintoul 2001a). However,

Corresponding author address: Dr. Daniele Iudicone, Stazione Zoologica “A. Dohrn," Villa Comunale 1, 80121 Naples, Italy. E-mail: iudicone@szn.it there are many unanswered questions regarding the formation, ventilation, and circulation characteristics of these water masses, in large part owing to data sparcity in the region. Our main goal in this study is to arrive at an improved understanding of the origin, pathways, and dynamical controls of the export of AAIW into the Pacific Ocean.

Two scenarios have been previously presented in the literature for the formation of AAIW. The first is a circumpolar scenario (e.g., Sverdrup et al. 1942; Sørensen et al. 2001), and the second is a local formation scenario (e.g., McCartney 1977; Talley 1996; England et al. 1993). The first scenario involves a relatively zonally homogeneous production and export (via diffusive pro-

DOI: $10.1175 / J P O 2985.1$

(C) 2007 American Meteorological Society 
cesses) of AAIW from the subpolar front. The second scenario implies local formation via air-sea fluxes predominantly in the southeast Pacific, with subsequent ventilation of the Pacific and Atlantic Ocean basins, the latter via Drake Passage (see also Piola and Georgi 1982; McCartney 1982).

There is as yet no consensus regarding the pathways of export of AAIW into the Pacific. Tomczak and Godfrey (1994) and Talley (1996) suggest that AAIW leaves the Southern Ocean in the southeastern corner of the Pacific, as this pathway is consistent with the low salinity of the isopycnal surface corresponding to AAIW. On the other hand, Reid $(1986,1997)$ argued for a flow at 800-m depth turning northward from the Antarctic Circumpolar Current (ACC) at $110^{\circ} \mathrm{W}$. Russell and Dickson (2003) used World Ocean Circulation Experiment (WOCE) tracer distributions to argue for an exchange scenario consistent with that of Reid (1986, 1987).

The uncertainties regarding the export and ventilation of AAIW have served as an obstacle to a more direct consideration of the physical processes that control the export itself. Gnanadesikan (1999) and Marshall and Radko (2003) argue that a dynamical balance exists in the ACC between the northward Ekman transport and the southward transport due to the eddy residual circulation, thus invoking mesoscale dynamics as playing a role in the export of AAIW. Interestingly, the study of the transient response to an abrupt closing of the Indonesian Throughflow by Hirst and Godfrey (1994) showed that pycnocline depth perturbations in the western equatorial Pacific propagate eastward via a second baroclinic Kelvin wave mode and bifurcate at the eastern coast, with coastal Kelvin waves subsequently propagating to the tip of South America while radiating Rossby waves westward into the eastern subtropical gyre. Farther west, the structure of the potential vorticity (PV) field, shaped by the wind-forced Sverdrup circulation, exhibits eastward advected Rossby waves preventing pycnocline depth perturbations from penetrating further into the subtropical gyre. The eastern part of the South Pacific subtropical interior gyre acts therefore as a north-south oriented Rossby waveguide able to connect the southeast corner of the Pacific with the western equatorial region. This particular dynamical framework is used here as a starting point for the investigation of the dynamics of the AAIW export.

To address the central question of this study (location, pathways, and dynamical controls of AAIW export), we use both analyses of ocean measurements and an ocean model. For data, we rely on the relatively newly available National Oceanographic Data Center

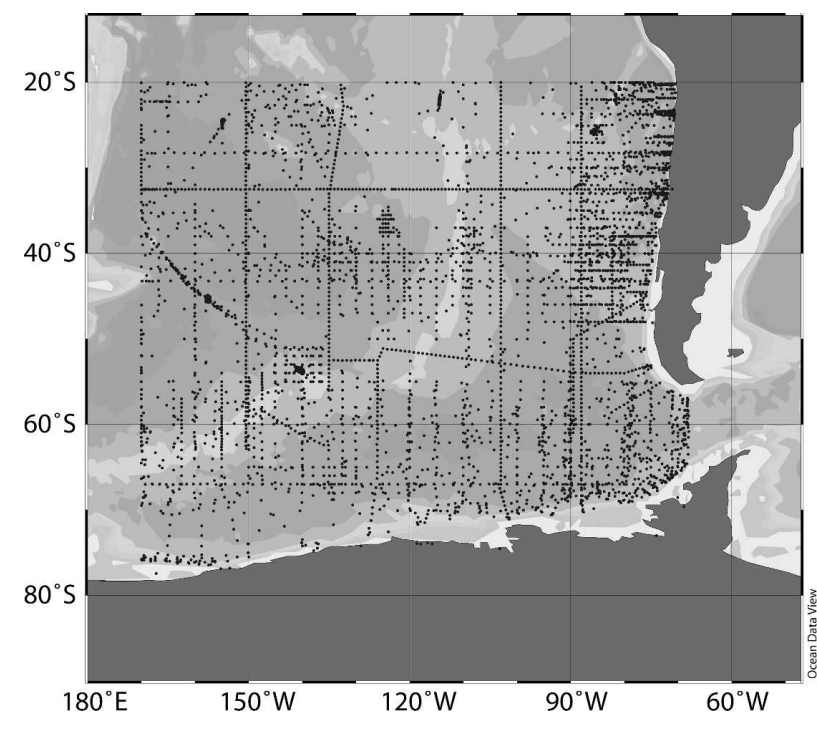

FIG. 1. Spatial distribution of the NODC01 data used in the analysis in section 2 .

(NODC01) dataset (Conkright et al. 2002). The use of a model, in conjunction with Lagrangian diagnostics, allows us to characterize the circulation of the upper ocean in the region of interest, and to understand its relation to the basin-scale circulation. In addition, sensitivity studies with the ocean model provide a means to gain insight into the dynamical controls of the export.

This paper is organized as follows. Section 2 describes, on the basis of in situ data, the circulation pattern and tracer distributions associated with AAIW in the southeast Pacific. In section 3 an ocean model simulation is analyzed in order to help to interpret the data and to further our goal of articulating a ventilation scenario for AAIW export. In section 4 the sensitivity of the flow to a variety of model parameter settings and forcing configurations for the same model is examined. Sections 5 and 6 consist of a discussion and conclusions, respectively.

\section{The southeast Pacific circulation from in situ data}

The hydrographic station data (high- and low-verticalresolution CTD data and bottle data) used in this study are the totality of the publicly available data for the period from 1941 to 2001 in the region $20^{\circ}-80^{\circ} \mathrm{S}, 170^{\circ}-$ $68^{\circ} \mathrm{W}$ (Fig. 1). They were obtained from the National Oceanographic Data Center (Conkright et al. 2002). ${ }^{1}$ Stations where measurements did not extend to a depth of at least $1000 \mathrm{~m}$ were excluded. NODC quality flags

\footnotetext{
${ }^{1}$ Nevertheless, these data are biased toward austral summer and early autumn (Conkright et al. 2002).
} 
were used to filter the data. The interpolation of data was done on neutral density surfaces (McDougall 1987) using the Ocean Data View (ODV) software utility (Schlitzer 2004). All subsequent tracer fields are projected on these surfaces.

In the present work three different neutral density surfaces $(27.0,27.25,27.8)$ in this region are considered in order to characterize the vertical current structure in the upper $1500 \mathrm{~m}$. The 27.25 neutral density surface corresponding to AAIW was chosen after visual inspection of salinity profiles to trace the intermediate salinity minimum in the southeast Pacific.

\section{a. Subsurface circulation}

The depth of the 27.0 neutral surface is shown in Fig. 2a. The subtropical gyre is centered around $20^{\circ} \mathrm{S}$ while a sharp front extends along $40^{\circ} \mathrm{S}$. The dynamic height at $10 \mathrm{~m}$ (Fig. 2b, referenced to 2500-m depth) shows that the surface geostrophic circulation is essentially zonal, with two main fronts-one associated with the ACC at approximately $55^{\circ} \mathrm{S}$, the other at the southern boundary of the subtropical gyre at about $38^{\circ} \mathrm{S}$. The latter feature corresponds to the 2.22 dyn $\mathrm{m}$ isopleth. Between the two fronts a secondary circulation appears to separate from the ACC at the East Pacific Rise, at approximately $140^{\circ} \mathrm{W}$, flowing northeastward to $120^{\circ} \mathrm{W}$ where it becomes a weak zonal flow. This circulation joins an eastward-flowing water mass (West Drift) at $40^{\circ}-50^{\circ} \mathrm{S}$, $120^{\circ} \mathrm{W}$; upon reaching the coast of Chile this drift bifurcates into a northward and southward flow (the Peru-Chile Current and the Cape Horn Current, respectively, although the latter is not well defined in Fig. 2b) (see also Reid 1997; Rojas et al. 1995; Stramma et al. 1995; Strub et al. 1998; Shaffer et al. 2004; Tomczak and Godfrey 1994; Chaigneau and Pizarro 2005). The NODC01 dataset, which includes all available data, thus allows for a characterization of structures that were not well defined with pre-WOCE data (e.g., Stramma et al. 1995, their Fig. 1).

\section{b. The AAIW circulation}

The depth of the AAIW 27.25 neutral surface is shown in Fig. 2c. The ACC front is clearly evident as an elongated structure along $55^{\circ} \mathrm{S}$. The signature of the subtropical gyre can be seen in the deepening of this surface toward the southwestern part of this region. This feature appears to have two cores with each exhibiting a local depth maximum-one at $35^{\circ} \mathrm{S}$ corresponding to the wind-driven Sverdrup flow and a second, deeper core at $47^{\circ} \mathrm{S}$, which most likely corresponds to a wind-driven recirculation gyre. The eastward extension of the northern core is larger than the eastward extension of the southern core, a feature again consis- tent with a recirculation gyre imbedded in a Sverdrup flow (Pedlosky 1998). In particular, the northern core reaches at least $85^{\circ} \mathrm{W}$, while the southern core only reaches $100^{\circ} \mathrm{W}$. A plateau or flattening of this neutral surface is observed between $42^{\circ}$ and $50^{\circ} \mathrm{S}, 100^{\circ} \mathrm{W}$ and the coast.

A map of the $700 \mathrm{~m} / 2500 \mathrm{~m}$ dynamic topography is shown in Fig. 2d. The ACC elongation and the southern core of the subtropical gyre $\left(48^{\circ} \mathrm{S}\right)$ are clearly recognizable at this depth. The dynamic height between $100^{\circ} \mathrm{W}$ and the Chilean coast reveals the presence of northward flow leaving the subpolar front, with a diversion to the northwest north of $40^{\circ} \mathrm{S}$. A comparison with Fig. $2 \mathrm{c}$ reveals that a northward flow occupies the region characterized by the plateau and then crosses orthogonally the upper front at $40^{\circ} \mathrm{S}$. The presence of a plateau in density inhibits the existence of vertical shearing motions owing to thermal wind balance but does not exclude the possibility of a vertically coherent horizontal velocity field. It is only to the north of $40^{\circ} \mathrm{S}$ that the circulation follows the topography of the neutral surface. The circulation is found to be vertically coherent between 600 and $1000 \mathrm{~m}$ (not shown) from the subpolar front to $35^{\circ} \mathrm{S}$. South of $35^{\circ} \mathrm{S}$, we observe a southwestward displacement of the subtropical gyre with depth, with isopleths backing from northwestward to westward (Fig. 2). Additionally, it is worth noting that the northward deviation from the zonal path at $54^{\circ} \mathrm{S}, 97^{\circ} \mathrm{W}$ of both the geostrophic circulation and the 650-700-m neutral surface isobaths is not linked to any large-scale topographic feature.

It is constructive to consider how the circulation fields that we have inferred from the NODC data are comparable with the circulation scenarios on intermediate densities presented in previous studies (Reid 1986, 1997; Davis 1998, 2005). A map of geostrophic pressure at $900 \mathrm{~m}$ from the Autonomous Lagrangian Circulation Explorer (ALACE) floats (Davis 1998; their Fig. 6) exhibits large-scale features similar to those found in this study (Fig. 2d). Some of these features are (i) the existence of an ACC meander; (ii) a northward flow from the ACC to the subtropics at $120^{\circ} \mathrm{W}$, both coincident with the East Pacific Rise; and (iii) the presence of a closed recirculation around $140^{\circ} \mathrm{W}$. Nevertheless, in the NODC01 data we have identified clear evidence of a large-scale northward flow at $40^{\circ}-50^{\circ} \mathrm{S}$ between $100^{\circ} \mathrm{W}$ and the coast of Chile. This is in stark contrast to the circulation in this region described in the analysis of Davis (1998) where most of the isobars in the region between $50^{\circ}$ and $30^{\circ} \mathrm{S}$ intersect the coast of Chile, a consequence of the sparcity of their dataset in this region. However, the float dataset used by Davis (2005) shows flow pathways consistent with 

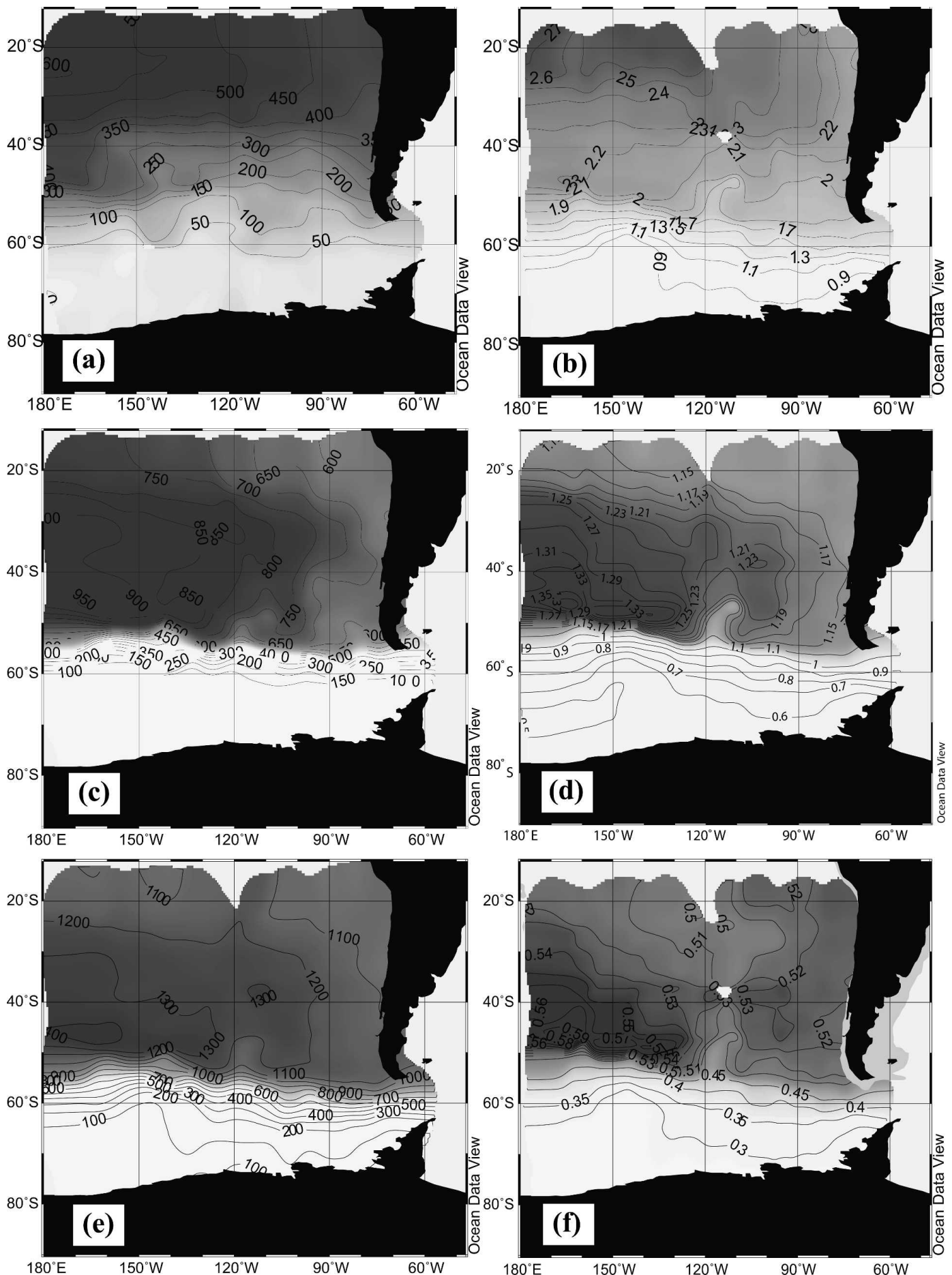

FIG. 2. Depths of three different neutral surfaces along with dynamics heights calculated on levels corresponding to the mean of the depth of the surface in the region shown. (The ODV gridding parameter is chosen to be 50 in all of the figures created with ODV software.) The first column shows the surface depth, and the second column shows the dynamic height (referred to $2500 \mathrm{~m}$; note the uneven isoline interval): (a) depth of the 27.0 surface; (b) dynamic height at $10 \mathrm{~m}$; (c) depth of the 27.25 surface; (d) dynamic height at $700 \mathrm{~m}$; (e) depth of the 27.8 surface; (f) dynamic height at $1500 \mathrm{~m}$. 
what is revealed by the NODC01 data. The analysis of pre-WOCE data, of Reid (1997), implies instead that the direction of the circulation east of $110^{\circ} \mathrm{W}$ is southward, with the direction of flow being the opposite of that identified here.

\section{c. Circulation at $1500 \mathrm{~m}$}

For the 27.8 neutral surface (Fig. 2e), the deep core of the subtropical gyre is centered at $48^{\circ} \mathrm{S}$ with a plateau located east of $100^{\circ} \mathrm{W}$. The associated circulation (Fig. 2f) reveals the deep gyre core, while vanishing currents are found to the east, compatible with a shadow-type eastern boundary regime (Pedlosky 1998; Huang and Qiu 1998). The circulation identified on the intermediate density horizon between $100^{\circ} \mathrm{W}$ and the Chilean coast is not found on this deeper layer. Thus, the northward transport in this region is localized in the vertical to intermediate layers.

In agreement with Huang and Qiu (1998), the circulation on the three density horizons discussed above shows the core of the subtropical gyre to shift to the southwest with increasing density. This feature is an expression of the beta spiral, based on potential vorticity conservation and thermal wind balance, through the southwestward strengthening of the wind-forced zonal shear capable of building up western recirculation regimes with deep constant potential vorticity pools (Rhines and Young 1982a,b). Furthermore, the meridional spatial data sampling reveals that the deep core of the subtropical gyre, as seen in Fig. 2e and Fig. 2f, is still well defined at $1500 \mathrm{~m}$. At this depth the core is now located close to (within a few degrees of) the subpolar front. The presence of such a deep subtropical recirculation core can be accounted for by its connection to an Antarctic circumpolar flow (Haynes 1985).

\section{d. Tracer distribution on the AAIW isopycnal and observed circulation}

To test whether the northward circulation feature identified on the AAIW horizon is coherent with tracer measurements from the same NODC dataset in this region, we consider tracer distributions projected on the 27.25 neutral surface. We begin with the salinity distribution (Fig. 3a) and consider its relation to the circulation implicit in Fig. 2d. The ACC is identified by the sharp front near $55^{\circ} \mathrm{S}$, which corresponds roughly to the winter outcrop near $57^{\circ} \mathrm{S}$ (see section $2 \mathrm{f}$ ). To the south of this front/outcrop, surface values of salinity are shown. Across $50^{\circ} \mathrm{S}$, the zonal structure reveals salinity decreasing between $180^{\circ} \mathrm{W}$ and the Chilean coast, with minimum values confined between $100^{\circ} \mathrm{W}$ and the coast, corresponding to the injection of the freshest
AAIW (salinity of about $34.25 \mathrm{psu}$ ) from the ACC into the subtropical gyre. Furthermore, the meridional gradient of salinity between the subpolar front and $50^{\circ} \mathrm{S}$ in this region is weaker than it is for the region farther to the west. Between $55^{\circ}$ and $20^{\circ} \mathrm{S}$, the northward transport of the low salinity signal can be seen, with an indication of a westward transport near $30^{\circ} \mathrm{S}$. Maximum salinity values can be seen near $20^{\circ} \mathrm{S}, 70^{\circ} \mathrm{W}$ where the Chile-Peru Undercurrent flows along the American coast.

Next we consider oxygen on the same neutral surface (Fig. 3b). AAIW is known to have high oxygen concentration (Russell and Dickson 2003). As with salinity, a sharp front can be seen along $55^{\circ} \mathrm{S}$, corresponding to the northern flank of the ACC. Likewise, the zonal structure across $50^{\circ} \mathrm{S}$ reveals increasing oxygen concentration between $100^{\circ} \mathrm{W}$ and the Chilean coast, which corresponds to the weakening of the salinity gradient seen on the same surface. As with salinity, the oxygen maximum propagates northward, with the signal strongly present north of $40^{\circ} \mathrm{S}$. The oxygen is minimum at approximately $20^{\circ} \mathrm{S}$ within $1000 \mathrm{~km}$ of the South American coast, with this feature corresponding to the Peru-Chile Undercurrent signature (Fig. 3b).

The Southern Ocean is a region of substantial upwelling of deep waters that are rich in nutrients. Iron limitation of the phytoplankton blooms at the surface results in different rates of removal of $\mathrm{Si}$ and $\mathrm{NO}_{3}$ in surface waters of the Southern Ocean (Brzezinski et al. 2003). The distribution of the Si on the AAIW horizon (Fig. 3c) shows, in fact, large minima along the main ACC path and high values in the Antarctic divergence south of it. The low Si signal is observed to propagate northward into the South Pacific in a manner consistent with the salinity and oxygen signals in the southeastern corner of the basin. The nitrate and phosphate distributions (not shown) are somewhat patchy, but are consistent with the Si pattern.

Taken together, the tracer distributions shown in Fig. 3 reveal patterns that are consistent with the circulation feature identified in Fig. 2 (see schematics in Fig. 4). Given that the three tracers shown are independent insofar as their sources and sinks are distinct, this indicates that the common structure in the region between $100^{\circ} \mathrm{W}$ and the Chilean coast between $40^{\circ}$ and $55^{\circ} \mathrm{S}$ is a robust feature and is not a peculiarity of any particular tracer. For the 27.25 neutral surface depth (Fig. 2c) and the tracers, the polar front represents a sharply defined structure between $180^{\circ}$ and $100^{\circ} \mathrm{W}$. Between $90^{\circ} \mathrm{W}$ (i.e., to the east of the deep extension of the subtropical gyre) and the coast of Chile the meridional gradient associated with the front is significantly weaker with tracer properties more like those of the subpolar front. 

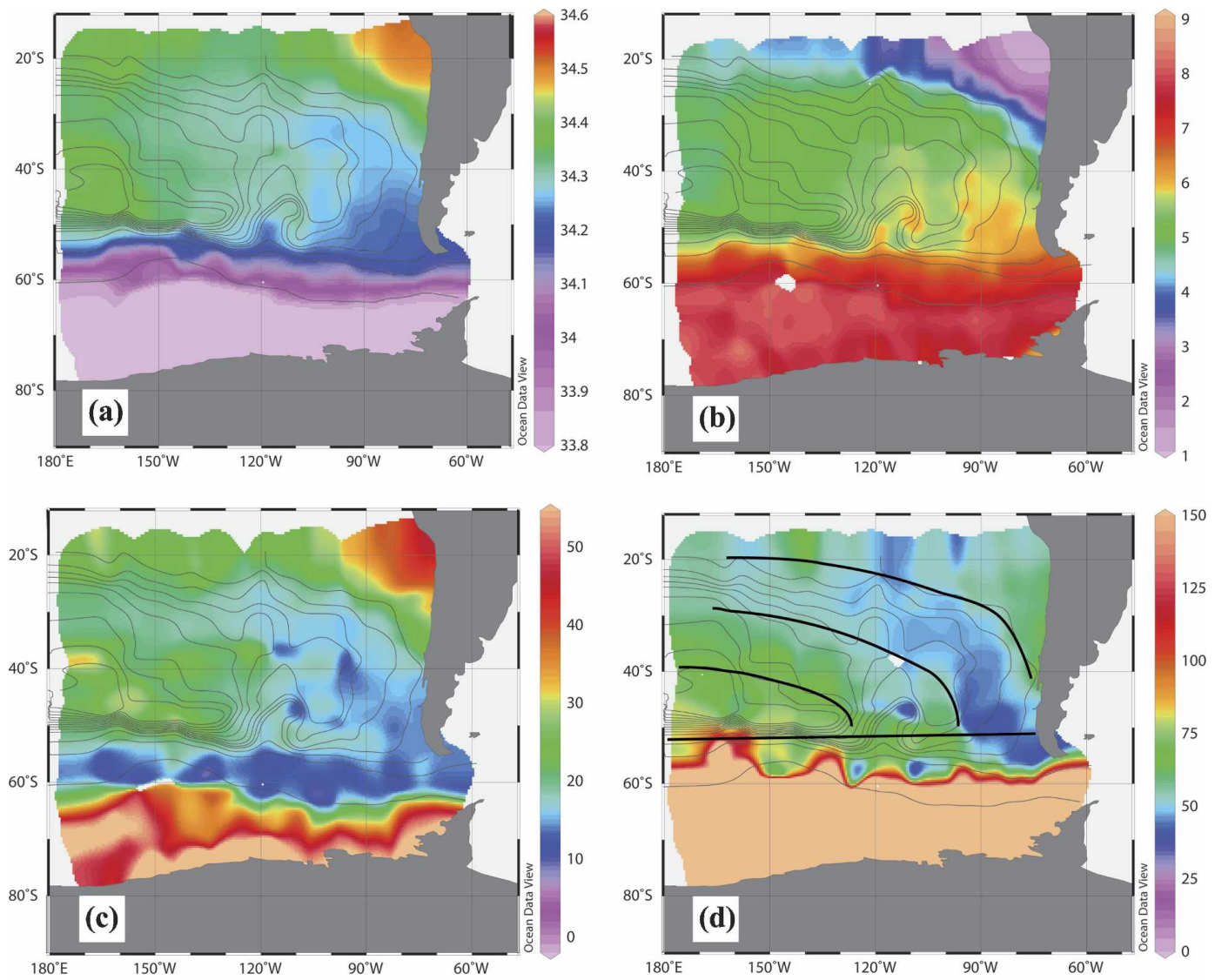

FIG. 3. Tracers from the NODC dataset projected onto the 27.25 neutral surface: (a) salinity, (b) oxygen (mL $\left.\mathrm{L}^{-1}\right)$, (c) silicate $\left(\mu \mathrm{mol} \mathrm{L}^{-1}\right)$, and (d) potential vorticity from NODC01 data projected onto the 27.25 neutral surface in color $\left(10^{-12} \mathrm{~m}^{-1} \mathrm{~s}^{-1}\right)$. The thin black contours show the dynamic height (dyn $\mathrm{m}$ ) superimposed with a contour interval of 0.02 dyn $\mathrm{m}$; contours less than 1.0 dyn $\mathrm{m}$ are not shown. The thick black contours have been drawn to emphasize the correspondence between the potential vorticity and the dynamic height over this region.

\section{e. Potential vorticity}

The PV distribution on the 27.25 neutral surface (Fig. 3d) reveals a large-scale pattern, consistent with what was found for the tracer distributions (Figs. 3a-c). The main difference between the PV and the tracer distributions can be seen in a distinct PV minimum observed at about $48^{\circ} \mathrm{S}, 85^{\circ} \mathrm{W}$, while another minimum is observed to the southeast, close to the coast of South America (e.g., Talley 1996). These extrema are, in fact, embedded in a low PV anomaly (values lower than $60 \times 10^{-12} \mathrm{~m}^{-1} \mathrm{~s}^{-1}$ ), whose southern boundary is a sharp zonal front along the ACC. This low PV signal propagates northward along the main flow (see also Fig. 2d) with a very good correspondence with the flow at $700 \mathrm{~m}$ as well as with the pattern of the tracers discussed above. High PV values are observed along $50^{\circ} \mathrm{S}$ in the region corresponding to the deep core of the subtropical gyre and in the Peru-Chile Undercurrent, with elevated values being due to the strong stratification present at those depths. It is also worth noting that the vertical current shear in the southeast Pacific (see Figs. 2b,d,f), with weak eastward subsurface flow and northward intermediate flow, is compatible with largescale PV conservation and thermal wind dynamics. A northward flowing intermediate layer, which maintains constant PV while moving over a deep ocean at rest, sees its upper interface deepening toward the equator, inducing an eastward flow in the upper layer compatible with thermal wind balance.

\section{f. AAIW origins}

Talley (1996) proposed a local origin of AAIW by ventilation, ${ }^{2}$ followed by a northward spreading, to explain the minimum in PV in the region to the north of the subpolar front in the southeast corner of the Pacific basin (see also Tsuchiya and Talley 1998). To address ventilation by the mixed layer of the PV minimum iden-

\footnotetext{
${ }^{2}$ Ventilation here is meant to be the ensemble of processes acting on a layer in contact with the mixed layer.
} 


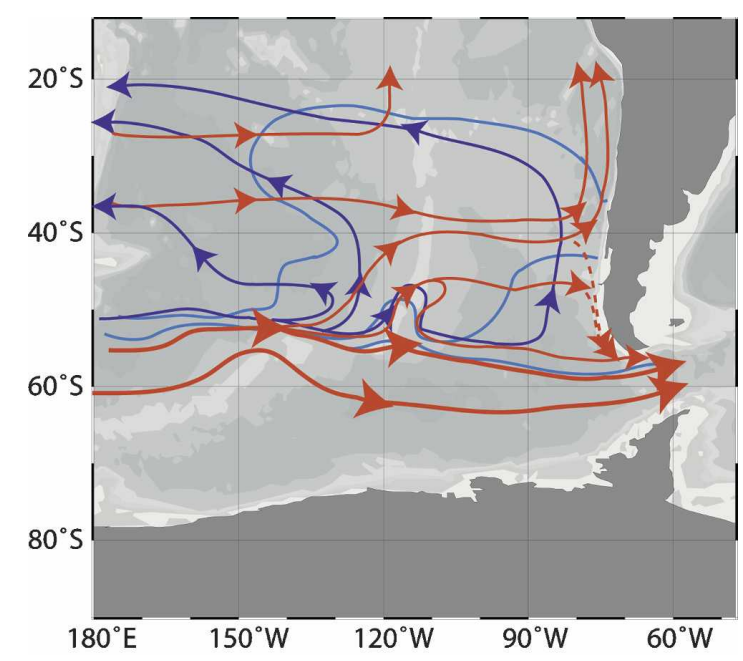

FIG. 4. Sketch of the surface (red arrows) and 700-m (blue arrows) mean circulations resulting from the data analysis (Fig. 2). The light blue lines summarize the salinity distribution on the AAIW neutral surface (Fig. 3a). The coastal circulation (dashed arrows) was deduced from the literature discussed in section 2 and via the model Lagrangian analysis (section 3).

tified in Fig. 3d, it is necessary to evaluate the winter mixed layer depth in the region of interest, together with the meridional position of the winter outcrop of the 27.25 neutral surface.

Figure 5 shows two independent estimates of the maximum mixed layer (ML) depth for the region of interest (de Boyer Montégut et al. 2004, their Fig. 14). The first estimate (Fig. 5a) is calculated using the depth of the $95 \%$ oxygen saturation surface (see also Hanawa and Talley 2001), and the second (Fig. 5b) is calculated using a temperature-based method. [The details on the data spatial and time distribution and on the analysis methods can be found in de Boyer Montégut et al. (2004).] Both reveal a maximum ML depth near $55^{\circ} \mathrm{S}$, $90^{\circ} \mathrm{W}$ with a value of approximately $350 \mathrm{~m}$ in the first case and $450 \mathrm{~m}$ in the second case. In the first case the minimum is relatively isolated, but in the second it is contiguous with a zonally oriented band of relatively large ML values.

There is no net separation between the regions of PV minima (Fig. 3d) and maximum ML (Fig. 5). Nevertheless, the difference in location between the northernmost absolute PV minimum ( $48^{\circ} \mathrm{S}$, see Fig. $\left.3 \mathrm{~d}\right)$ and the absolute maximum ML depth $\left(55^{\circ} \mathrm{S}\right.$, see Fig. 5) would favor a nonlocal AAIW formation origin. On the contrary, the southern PV minimum, located around $55^{\circ} \mathrm{S}$, indicates a more local formation, but this water mass enters Drake Passage rather than the Pacific. Additionally, the location of the ML maximum depth region appears as a large-scale open-ocean feature rather than the coastal process proposed by England et al. (1993).
These statements have to be kept only as indicative owing to the sparse winter-spring data in this region, and further studies are needed to address the issue.

Of equal importance for the question of whether ventilation is local, the outcrop line of the 27.25 surface during austral winter (computed from the inspection of single CTD profiles and depicted on Fig. 5) is found to be to the south of the ML depth maximum, at about $57^{\circ} \mathrm{S}$. This serves to underscore that the density horizon corresponding to the PV minimum is not directly in contact with the base of the region of maximum ML depth. Preliminary analysis of the ARGO floats released in the region indicates a latitude of outcrop for the 27.25 surface, consistent with that identified with the NODC01 data. Last, when considering the circulation at the surface and $700 \mathrm{~m}$, the outcrop appears to occur in a region of the ACC within the main ACC stream, flowing toward Drake Passage.

Climatology of the Ekman pumping has been computed using monthly values of the wind stress curl derived from the European Remote Sensing Satellite (ERS)-1/2 scatterometer data [1991-99, Centre de Recherche et d'Exploitation Satellitaire (CERSAT) data] in order to identify whether there is evidence of winddriven subduction of AAIW. The annual-mean Ekman pumping distribution (not shown) reveals a line of zero pumping oriented zonally along $50^{\circ} \mathrm{S}$, with upwelling to the south and downwelling to the north. Thus, the southernmost part of the PV minimum region coincides roughly with a region where the annual mean vertical/ wind-driven component of subduction is not important. The seasonal variability in Ekman pumping, however, reveals that the zero line moves to approximately $56^{\circ} \mathrm{S}$ in winter (September, see Fig. 5). Nevertheless the outcrop line of the 27.25 surface is to the south of the southernmost seasonal excursion of the zero Ekman pumping line.

Analyzing tracer data, Russell and Dickson (2003) proposed that along $90^{\circ} \mathrm{W}$ AAIW is not the newest AAIW in the South Pacific; that is, it is at least mixed with older waters. Comparing the salinity and oxygen maps (Fig. 3) and considering the AAIW pathway in Fig. $2 b$ and Fig. 4, the fresher AAIW is actually entering the South Pacific east of $85^{\circ} \mathrm{W}$. In fact, the results presented here and in Russell and Dickson (2003) can also be interpreted as showing that AAIW is at most partially ventilated in the southeastern Pacific. This partial ventilation could occur via vertical diffusive processes at the base of the mixed layer (M. S. McCartney 2003, personal communication).

In conclusion, the analysis of the NODC01 dataset suggests that the Pacific AAIW enters the basin mostly in the southeast corner. The analysis of data does not 

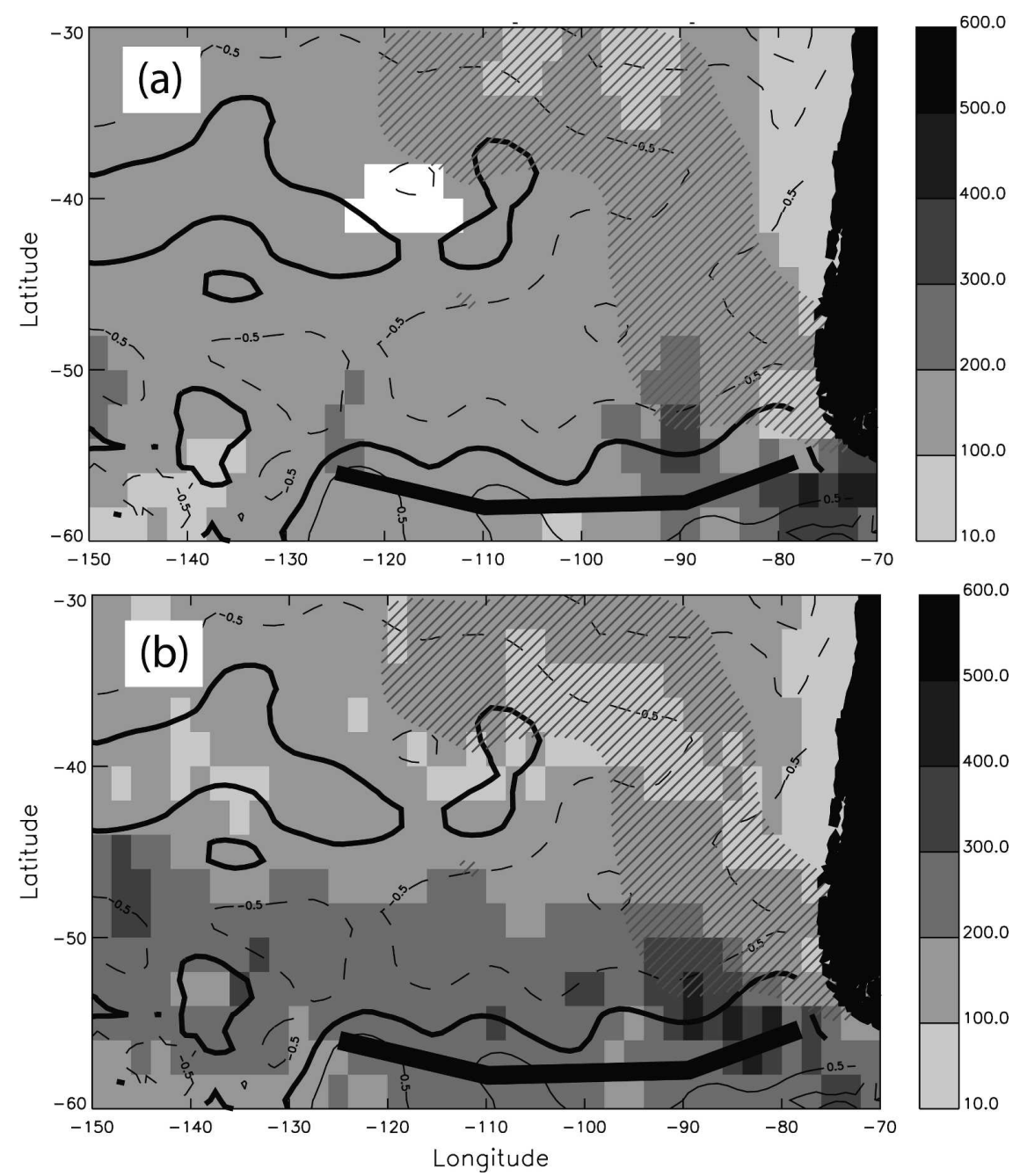

FIG. 5. Mean Ekman pumping in September from the ERS1/2 scatterometer data (1991-99, CERSAT data). Dashed lines indicate negative values. The thick black line represents the austral winter outcrop of the AAIW neutral surface derived from a visual inspection of NODC01 and Argo data. The PV minimum is superimposed (hatched region). In gray are two independent estimates of the maximum ML depth [details can be found in de Boyer Montégut et al. (2004)]: (a) mixed layer depths (m) defined as the depth of 95\% oxygen saturation surface (see Hanawa and Talley 2001) and (b) mixed layer depths (m) calculated using a temperature-based method.

point to a local origin of the Pacific AAIW. In fact, the data are consistent with a circulation schematic whereby the water, which is locally ventilated in the ACC in the Pacific sector, is exported via Drake Passage to the Atlantic sector (e.g., Hanawa and Talley 2001; Cunningham et al. 2003).

\section{On the baroclinic export of the AAIW: A modeling study}

\section{a. Model description}

The ORCA2-Louvain-la-Neuve Sea Ice Model (LIM) ice-ocean coupled model consists of the global
ORCA2 configuration of Océan Parallélisé (OPA) 8.2 (Madec et al. 1998) and the LIM coupled model (Fichefet and Morales Maqueda 1997), a fully dynamical-thermodynamical sea ice model (see Timmermann et al. 2005; D. Iudicone et al. 2005, unpublished manuscript, hereinafter IUD05). The model has 31 vertical levels and a horizontal resolution of $2^{\circ} \cos$ (latitude) except in the equatorial regions, leading to a resolution of approximately $1^{\circ}$ in the Southern Ocean. Although the model is not eddy permitting, it represents a substantial improvement in resolution relative to previous modeling studies of the AAIW in the South Pacific (e.g., Sørensen et al. 2001; Saenko et al. 2003). 


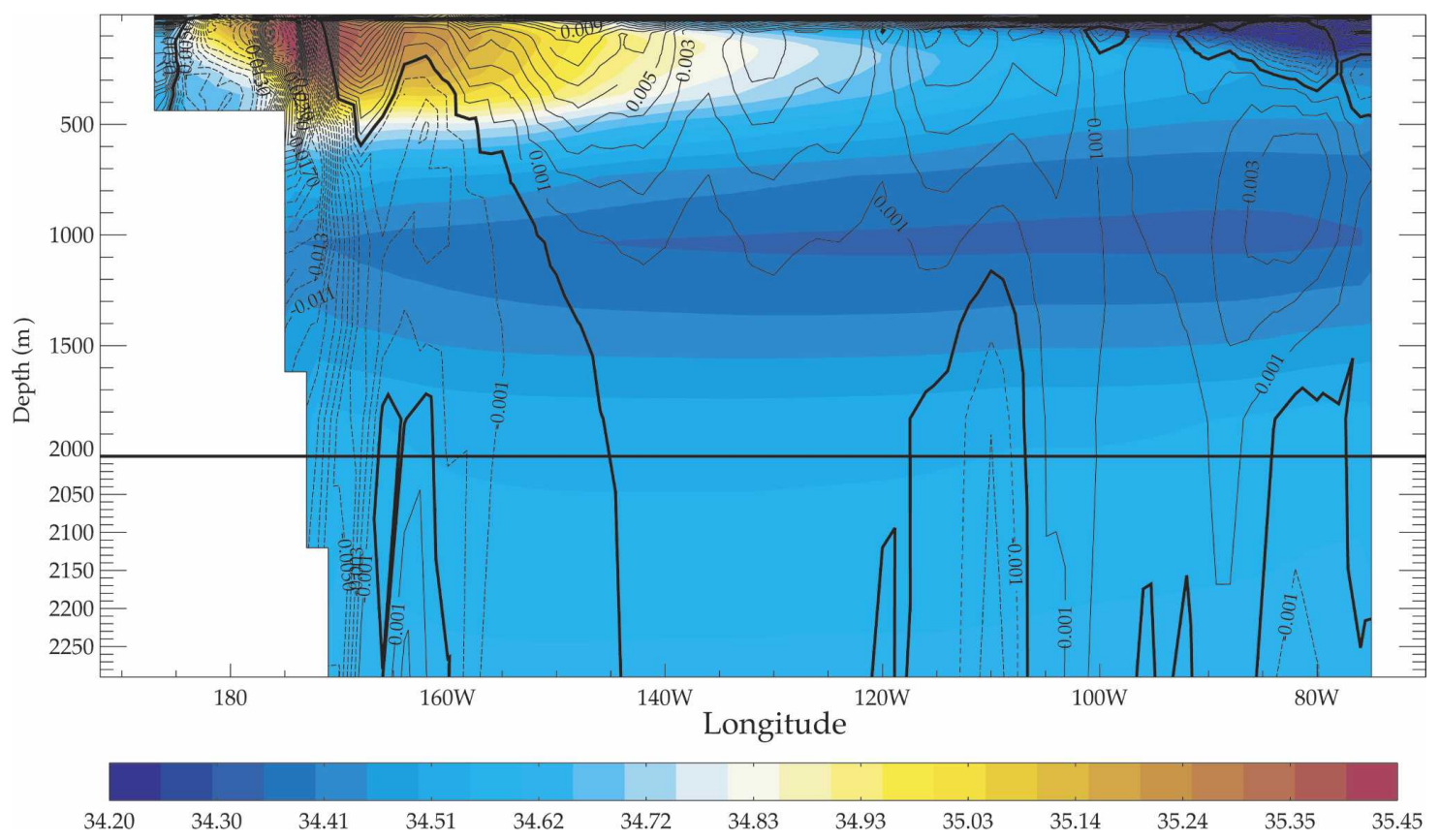

FIG. 6. In color, zonal section of salinity at $43^{\circ} \mathrm{S}$ in the ORCA2-LIM model (model year 1501, annual mean). Isopleths are the corresponding meridional velocity $\left(\mathrm{m} \mathrm{s}^{-1}\right)$.

After 1500 years of spinup (without acceleration), the model has reached an equilibrium state. In a parallel study (IUD05) the model circulation has been validated using transient tracers. There the simulated chlorofluorocarbon (CFC) inventories along WOCE P18 section in the South Pacific show very good agreement with the CFC inventories measured during the WOCE campaign (Fine et al. 2001), and the simulated ventilation of the upper ocean reveals a marked improvement over the inventories simulated by the models participating in the Ocean Carbon-Cycle Model Intercomparison Project (Dutay et al. 2002).

\section{b. The circulation associated with the AAIW injection into the South Pacific}

The model's salinity distribution as well as the meridional component of circulation for a section at $43^{\circ} \mathrm{S}$ across the entire Pacific basin in shown in Fig. 6. The salinity field is characterized by two subsurface minima: the first localized to the eastern side of the basin at approximately $150-\mathrm{m}$ depth, a signature of the subsurface salinity minimum water (SSMW) consistent with observations (e.g., Schneider et al. 2003; Karstensen 2004), and the second, a less intense minimum at intermediate depth (approximately $1000 \mathrm{~m}$ ), elongated zonally along the whole section. This second minimum is the signature of the AAIW circulation. This salinity minimum associated with AAIW is deeper (in both depth and density space) than the observed salinity minimum, and the salinity values characteristic of the salinity minimum are larger by approximately $0.2 \mathrm{psu}$ than observation values (Sloyan and Rintoul 2001a).

On the western side of the basin, the southward flow of the western boundary current is associated with the highest salinity values along the section (Fig. 6). At depth, the southward flow is the return flow of the Pacific Deep Water, which leaves the basin on its way to rejoining the ACC. Between $170^{\circ}$ and $100^{\circ} \mathrm{W}$, the wind-driven gyre is characterized by several northward currents that are surface intensified with velocities vanishing at a depth of approximately $1200 \mathrm{~m}$. On the eastern side of the basin, a subsurface current is found to flow southward in the upper $400 \mathrm{~m}$. Below it, between 400 and $1500 \mathrm{~m}$, a northward flow occupies the region between $100^{\circ} \mathrm{W}$ and the Chilean coast, with velocities up to $0.0035 \mathrm{~m} \mathrm{~s}^{-1}$ and a transport of $2.5 \mathrm{~Sv}\left(\mathrm{~Sv} \equiv 10^{6}\right.$ $\mathrm{m}^{3} \mathrm{~s}^{-1}$ ), consistent with the estimate for the supply of new AAIW given by Sloyan and Rintoul (2001a). The AAIW salinity minimum is partly linked to the deepest part of the wind-driven gyre in the center of the basin, but in the easternmost region is clearly related to the observed intermediate flow. This current is bounded above by a counterflow at the surface, suggesting the existence of a baroclinic current system, with a southward flow in the upper layer and a northward one at intermediate depths. The latter current appears in the annual mean as a relatively broad (large scale) and 
weak flow. In fact, at $43^{\circ} \mathrm{S}$ it has a pronounced seasonal variability, with amplitude of as much as $50 \%$ of the total transport (not shown), with instantaneous velocities up to $0.01 \mathrm{~m} \mathrm{~s}^{-1}$. During the months from January to June, there is a southward coastal flow over the upper $1500 \mathrm{~m}$. This southward flow separates from the coast during the second half of the year, while progressively weakening through the end of the year. The seasonal cycle of this current is outside of the scope of this study and is left as a subject for further investigation.

The relation of the flow observed on the section at $43^{\circ} \mathrm{S}$ and the three-dimensional circulation field in the South Pacific has been characterized by means of quantitative offline Lagrangian diagnostics (Blanke and Raynaud 1997), which provide a means of characterizing water mass pathways. The origins and fate of the two cores of the baroclinic current at $43^{\circ} \mathrm{S}$ have been quantified by integrating Lagrangian trajectories both backward and forward in time. By releasing particles in the AAIW current core (in a zonal band at $43^{\circ} \mathrm{S}$ between $90^{\circ} \mathrm{W}$ and the coast, see Fig. 6) and integrating forward in time, it is found that approximately $80 \%$ of the AAIW flow reaches $10^{\circ} \mathrm{S}$, following the northern flank of the subtropical gyre and reaching the New Guinea Coastal Undercurrent.

Integrating trajectories backward in time until particles reach either a Tasmania-Antarctica section or $43^{\circ} \mathrm{S}, 56 \%$ of the AAIW is found to originate in the ACC, north of the subantarctic front (SAF) (dense SAMW), and $34 \%$ to originate at $43^{\circ} \mathrm{S}$ in the western boundary current east of New Zealand. Most of AAIW thus originates as SAMW flowing north of the subpolar front, which has become denser along the pathway. Moreover, there is no evidence for intersection of the trajectories with the mixed layer in the southeast Pacific for calculations performed with the time-reversed circulation fields.

The subsurface southward flow, shown schematically by the dashed arrows in Fig. 4, has been traced back in time with Lagrangian trajectories from $43^{\circ} \mathrm{S}$ to two sources: a zonal section across $32^{\circ} \mathrm{S}$ and the ACC (a meridional section between Antarctica and Tasmania). The surface flow has been found to have a transport of about 1.1 Sv and a density $\sigma_{0} \sim 26.2$. This flow corresponds to the southern flank of the West Drift and has its origins as a shallow branch of the ACC (Fig. 4). Moreover, along the Australia-Antarctica section it is found to be at the surface (depth $<100 \mathrm{~m}$ ) south of the $\mathrm{SAF}$ at $55^{\circ} \mathrm{S}$ and of the same density as the Upper Circumpolar Deep Water (Sloyan and Rintoul 2001b). This indicates that the Ekman transport has exported this water from the ACC core to its northernmost front.

\section{c. Model tracer fields on model AAIW horizon}

To investigate how the model fields compare with the observations presented in section 2 , model tracer fields have been projected onto the 27.4 neutral surface (Fig. 7: McDougall 1987; Jackett and McDougall 1997), the model surface corresponding to the salinity minimum. This allows for a validation of the structure of the penetration of the salinity minimum from the Southern Ocean into the South Pacific and, specifically, how the pathway identified using the Lagrangian tracers is manifested for various properties associated with this surface.

On the basin scale, the salinity distribution on the 27.4 neutral surface in Fig. 7a exhibits isopleths directed from southwest to northeast between $50^{\circ}$ and $30^{\circ} \mathrm{S}$. This tilt results from the wind-driven advective-diffusive circulation that advects the tracer around the gyre. Therefore, the isopleths are situated farther south in the west than in the east, indicating a preferential northward injection of salinity-minimum waters to the east. Farther to the north, this east to north inclination decreases, as this corresponds to the shadow zone region where velocities are lower on this surface.

The depth of the 27.4 neutral surface is shown in Fig. $7 \mathrm{~b}$. The maximum depth associated with the deep core of the subtropical gyre circulation is found to reach approximately $50^{\circ} \mathrm{S}$, in agreement with the observations in section 2. Furthermore, as in the NODC data, the eastern extension of the subtropical gyre structure is consistent with data in that it extends to the American coast at $35^{\circ} \mathrm{S}$, while at $50^{\circ} \mathrm{S}$ it only reaches $110^{\circ} \mathrm{W}$. To the east of $110^{\circ} \mathrm{W}$ along $50^{\circ} \mathrm{S}$, the zonal gradient of the depth of the 27.4 surface is very small, again consistent with observations.

The PV distribution associated with the same neutral surface is shown in Fig. 7d. A striking feature is the local minimum that extends meridionally from $55^{\circ}$ to $35^{\circ} \mathrm{S}$. Along $50^{\circ} \mathrm{S}$, the $\mathrm{PV}$ minimum is found between $100^{\circ}$ and $80^{\circ} \mathrm{W}$. This minimum coincides with the region of relatively uniform depth of the 27.4 surface identified in Fig. 7b, and is found in the same location as in the data. Dynamically, the associated weak meridional PV gradient helps to break dynamical constraints on meridional transport, and allows northward transport of waters and offers a window for meridional injection of subpolar frontal waters into the South Pacific. This window is imbedded in the large-scale gyre circulation between an eastern region and a western recirculation-type gyre and is not connected to either eastern or western boundaries. In contrast, a PV maximum is found farther west in the Pacific, corresponding to the deepest recirculation region of the subtropical 

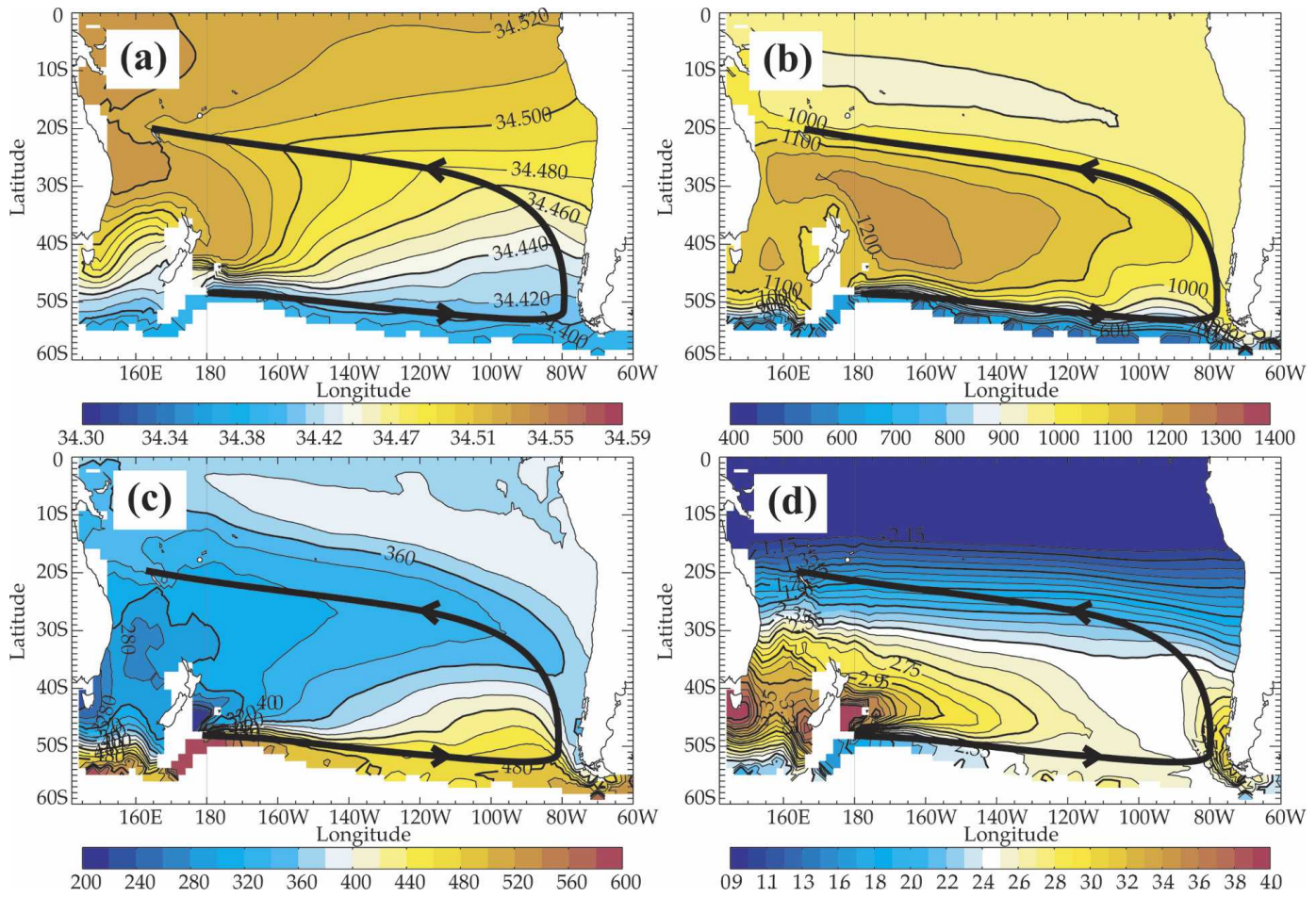

FIG. 7. Model properties on the 27.4 neutral surface in the ORCA2-LIM model (model year 1501, annual mean). A sketch of the AAIW Lagrangian easternmost pathway (see text) is superimposed on all of the figures: (a) salinity, (b) depth (m), (c) layer thickness (m), and (d) PV.

gyre along $45^{\circ} \mathrm{S}$, consistent with a stronger deep stratified pycnocline and consistent with what was identified in observations (Fig. 3).

The model does not generate local ventilation of the neutral surface corresponding to the minimum of salinity observed in the far eastern South Pacific. The shape of the neutral layer (Fig. 7b) is qualitatively similar to the shape of the observed AAIW layer (Fig. 2c) and reveals an intrusion of large layer thickness (weak stratification, see Fig. 7c) from the subpolar front into the region, seen in Fig. 2c, between the eastern extent of the subtropical gyre along $50^{\circ} \mathrm{S}$ and the South American coast. The protrusion is interesting in that the meridional thickness gradient compensates the variation of the Coriolis parameter $f$ in a way to drastically reduce the meridional $\mathrm{PV}$ gradient in this region (Fig. 7c).

To summarize the analysis of the steady-state model circulation fields, there is a baroclinic current associated with the injection of AAIW into the South Pacific. The water participating in this baroclinic flow structure originates from the zonally oriented circulation along the subpolar front. The analysis of tracers on the AAIW horizon reveals a very good correspondence between the large-scale patterns in the model with observations from the NODC data. In particular, the injection of AAIW occurs in the eastern part of the South Pacific, where the depth of the neutral surface exhibits almost no zonal gradient between $100^{\circ}$ and $80^{\circ} \mathrm{W}$. The near-total absence of a meridional gradient in PV in this longitudinal band (i.e., the dynamical exchange window) is found also in the model. The model thus reveals that the dynamics of the intrusion of AAIW has to be understood in terms of a largescale circulation feature involving the subpolar front/ ACC.

\section{The baroclinic current response to local and remote forcing}

Having identified the existence of an exchange window in both the data and the model, we next consider a series of dynamically motivated sensitivity studies with the model (each 100 years long) in order to pursue the question of the dynamical controls of this export. The first sensitivity study, which we consider, is a "NOINDO" perturbation study with a closure of the Indonesian passages, that is, a case where a pycnocline depth perturbation originates in the western Pacific equatorial ocean. In section $4 \mathrm{~b}$ we will emphasize a second mechanism; namely, we will consider perturba- 

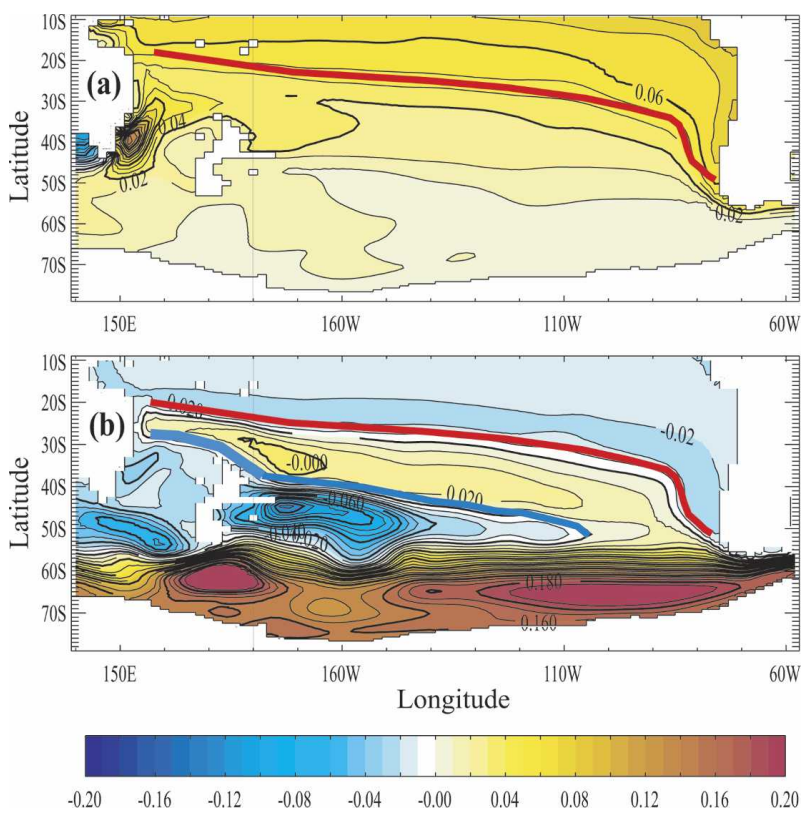

FIG. 8. South Pacific SSH anomaly (m) with respect to the control run. (a) NOINDO: The red line has been drawn in correspondence with the maximum horizontal gradient of the SSH anomaly. (b) GM2: The red line has been redrawn from (a). The blue line corresponds to the maximum horizontal gradient of the SSH anomaly in the southwest Pacific.

tions of the pycnocline in the Southern Ocean directly affecting the AAIW injection into the South Pacific.

\section{a. The role of equatorial dynamics in setting AAIW export}

The difference in sea surface height (SSH: a proxy for the pycnocline depth) between the NOINDO experiment and the control run (NOINDO minus control) is shown in Fig. 8a. The distribution of the SSH difference has the same characteristic basin-scale distribution for the South Pacific as the structure that Hirst and Godfrey (1993) found for the temperature perturbation at $370 \mathrm{~m}$ in their similarly configured perturbation study. The SSH difference with the model reveals a maximum of approximately $0.08 \mathrm{~m}$ in the equatorial Pacific and along the American coasts, associated with a deepening of the main thermocline in the midocean basin, and this is consistent with a shutdown of a net northward South Pacific mass transport due to the closing of the Indonesian Throughflow. A sharp front can be found along the northern flank of the subtropical gyre. This sharp front, characterized by the 0.04-0.05 SSH isopleth region, connects the southeast corner of the South Pacific to the equatorial region. This front corresponds in the model to regions where flow perturbations are maxima on intermediate horizons, a result consistent with the findings of Hirst and Godfrey (1993). In particular, at $43^{\circ} \mathrm{S}$, the baroclinic current system associated with the AAIW (centered near $85^{\circ} \mathrm{W}$ in Fig. 6) reveals a clear intensification, with a transport $25 \%$ larger than that found in the reference simulation for the flow of both immediately subsurface and intermediate waters (Fig. 9a). This serves to emphasize the large response in the rate of injection of intermediate water across $43^{\circ} \mathrm{S}$ for this perturbation study.

Despite the apparent continuity of the SSH anomaly from the western equatorial Pacific to the southeastern Pacific, the currents in the upper $400 \mathrm{~m}$ are equatorward up to $41^{\circ} \mathrm{S}$, where the bifurcation of the West Drift occurs, and poleward south of it (see section 3). Through use of the Lagrangian diagnostics as described in section 3 , it is found that the origins of waters in the upper $400 \mathrm{~m}$ and AAIW have not changed (they are still largely ACC waters). On the equatorward side of the front, the pycnocline depth perturbation is relatively large, whereas on the poleward side of the front the pycnocline depth perturbation is relatively small. The difference in horizontal depth gradients of the pycnocline along the front are associated with a change of the baroclinic geostrophic flow (via the thermal wind equilibrium), which explains the perturbations observed in the flow fields. Locally, in the region here under consideration, namely, between $40^{\circ}$ and $55^{\circ} \mathrm{S}$, $90^{\circ} \mathrm{W}$ and the South American coast, the front associated with the perturbation is oriented meridionally with an impact on the rate of AAIW injection. Thus, a nonlocal perturbation located in the equatorial region can strongly alter the AAIW export.

An insight into the dynamics of the large-scale perturbation of the pycnocline depth was obtained by Hirst and Godfrey (1994) via the analysis of the transient response to an abrupt closing of the Indonesian Throughflow. They found that second baroclinic-mode pycnocline depth perturbations can reach the tip of South America via the propagation of equatorial Kelvin waves, bifurcating at the eastern boundary, and then southward propagation of coastal Kelvin waves, which radiate waves westward into the interior as Rossby waves. The structure of the wind-driven Sverdrup flow field then acts as a waveguide with an equatorward-directed wave path, therefore inhibiting waves (i.e., the perturbation of the pycnocline depth) from penetrating farther west into the subtropical gyre (Rhines and Young 1982a,b; Luyten and Stommel 1986). Along the boundary between the perturbed and unperturbed region, a steady-state geostrophic flow/ underflow anomaly then builds up, reaching the subpolar front in the southeast Pacific. 

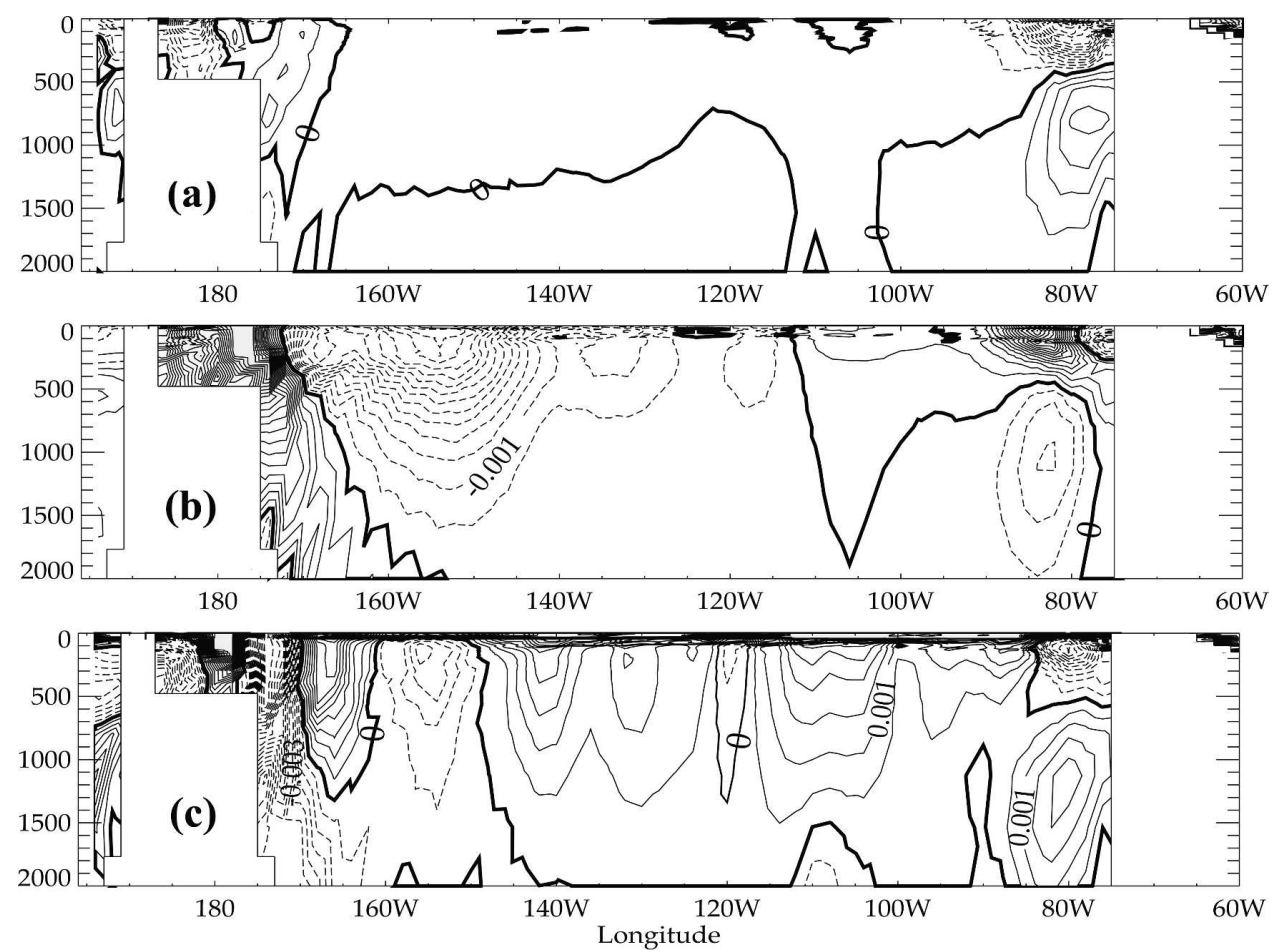

FIG. 9. Anomalies with respect to the control run in the meridional velocity field along a zonal section at $43^{\circ} \mathrm{S}$ (as in Fig. 6) in the ORCA2-LIM model (model year 100, annual mean; units: $\mathrm{m} \mathrm{s}^{-1}$, intervals: $5 \times 10^{-4} \mathrm{~m} \mathrm{~s}^{-1}$ ). (a) NOINDO - reference. (b) GM2 - reference. (c) SWIND2 - reference.

\section{b. The role of Southern Ocean dynamics in setting AAIW export}

We are now interested in considering whether extratropical pycnocline perturbations, specifically ACC perturbations, are also able to affect the AAIW export. This is considered within the context of a range of previous studies (e.g., Toggweiler and Samuels 1998; Gnanadesikan 1999; Borowski et al. 2002; Karsten et al. 2002; Marshall and Radko 2003), which have argued that there are two main perturbation mechanisms that can modify the pycnocline depth in the ACC: one being a modification of the eddy forcing and the other a modification of the Ekman transport.

\section{1) THE ROLE OF EDDIES IN THE EXPORT OF PACIFIC AAIW}

A numerical experiment (named GM2) has been performed for which the bolus transport coefficient in the Gent and McWilliams (1990) eddy parameterization is twice as large for the Southern Hemisphere as it is for the reference experiment, with values in the Northern Hemisphere kept the same as in the reference experiments. Note that, since the model eddy transfers depend on the local baroclinicity (Treguier et al. 1997) as well, it does not necessarily imply that the resulting eddy transports are 2 times as large.
Not surprisingly, the steepness of the ACC front is decreased for GM2 relative to the control run. In the Atlantic and Indian sectors, there is a large perturbation in SSH that corresponds to a flattening of the ACC isopycnals (not shown). A perturbation of opposite sign is also found all along the SAF. This feature can be understood in terms of a meridional shift of the fronts. On the other hand, in the Pacific the ACC SSH perturbation penetrates northward (Fig. 8b) far into the basin between $100^{\circ} \mathrm{W}$ and the Chilean coast, crossing the main fronts and reaching the subtropics east of New Zealand. In fact, for the GM2 case, the stratification change in the ACC owing to the increased eddy transfers propagates northward within a region bounded to the east by the same dynamic boundary as the one present in the NOINDO case (red curve in Figs. 8a and $8 \mathrm{~b})$. It is bounded to the west by the deep recirculating gyre (blue curve in Fig. 8b) where the velocity anomaly presents a coherent vertical structure over the first 1000 $\mathrm{m}$, and thus it is controlled by the first baroclinic Rossby-type mode. The subtropical intrusion of the ACC pycnocline anomaly alters the pycnocline slope along the red line in Fig. $8 \mathrm{~b}$ and thus weakens the northward flowing AAIW current in the eastern $\mathrm{Pa}-$ cific, even if the largest signal is in the west. In fact, as shown in Fig. 9b, this effect produces a significant $r e$ - 
duction of the mean advective AAIW export through the weakening of the baroclinic current system east of $100^{\circ} \mathrm{W}$. The anomaly is deeper than in the case where the perturbation has an equatorial origin (NOINDO), coherent with the southern origins of the pycnocline perturbation.

\section{2) The role of the Southern Ocean winds}

Two additional sensitivity experiments for which the wind stress in the Southern Ocean has been increased by $50 \%$ have been performed. The northward limit of the $50 \%$ perturbation is located at $50^{\circ} \mathrm{S}$ in the first experiment (SWIND1) and at $35^{\circ} \mathrm{S}$ in the second one (SWIND2) with a smooth transition to climatological values north of these latitudes. The goal of SWIND1 is to investigate the effects of a local forcing (the wind curl between $50^{\circ}$ and $40^{\circ} \mathrm{S}$ is changed) altering the ACC northward deviation (e.g., Nuñez and Rojas 1998). The aim of SWIND2 is to force both the circulation of the southern part of the subtropical gyre by changing the wind curl at midlatitudes and, above all, the depth and strength of the ACC (e.g., Borowski et al. 2002).

In SWIND1 the resulting anomaly at $43^{\circ} \mathrm{S}$ (not shown) presents an enhancement (weakening) of the intermediate current at $90^{\circ} \mathrm{W}\left(80^{\circ} \mathrm{W}\right)$. The opposite is observed at the surface. This result is somewhat different with respect to the experiments NOINDO and GM2 discussed previously. It corresponds to a westward shift of the entire baroclinic system, as observed in the seasonal cycle of the control run (see also Nuñez and Rojas 1998), without any change in the transport. This is due to the fact that the subtropical gyre deepens without increasing in strength (Haynes 1985), as well as to the shift westward of the different regimes (the red and green curves in Fig. 8b), owing to an increase of the Rossby wave speed. SWIND1 therefore shows how the local circulation is sensitive to changes in the local wind stress curl, which alters the current patterns but has no influence on the net baroclinic AAIW export.

The SWIND2 case presents a large SSH negative perturbation along the whole ACC that corresponds to an uplifting of isopycnals. The circulation perturbation at $43^{\circ} \mathrm{S}$ east of $90^{\circ} \mathrm{W}$ (Fig. 9c) is similar to the GM2 experiment (with only reversed signs, see Fig. 9b) with an enhancement of the baroclinic system at $80^{\circ} \mathrm{W}$. As in GM2, the perturbation is deeper than in the NOINDO case and is related to a northward intrusion of the ACC perturbation. A major difference with the GM2 experiment is the blocking of the northward extension of the SSH signal at about $35^{\circ} \mathrm{S}$ by the large zonal perturbation within the gyre produced by the wind stress curl modification.

\section{Discussion}

\section{a. A scenario for the dynamics of the AAIW export}

We wish to point out first that the different regions and fronts observed to characterize the propagation of tracers on the AAIW horizon are compatible with the existence of an eastern shadow zone (Luyten and al. 1983), western and eastern regimes (regimes defined in terms of Rossby wave propagation speeds), as is the case for PV (black curves in Fig. 3d). Interestingly, the dynamical significance of these regions also emerged in the sensitivity model study. Furthermore, Huang and Qiu (1998) provided an estimate of the wind-driven circulation in the South Pacific. On the AAIW horizon, the absence of local ventilation in their dataset generates a closed anticyclonic recirculation gyre in the western subbasin (the Rhines-Young PV pool) while in the east a region of zero flow is predicted, due to the presence of a shadow zone. In fact the northward flow, exporting the AAIW, is imbedded in and almost coincides with the shadow zone of Huang and Qiu (1998).

Second, nonfrictional large-scale meridional transports allow for the existence of a cross-gyre window (Schopp and Arhan 1986; Schopp 1988; Chen and Dewar 1993; Pedlosky 1998) only if certain specific dynamical conditions along the zero wind curl line are satisfied, notably an arrested Rossby wave condition. Once these conditions are satisfied, the circulation is able to connect the ACC to the subtropical gyre. These windows, based on blocked divergent Rossby waves by zonal mean currents, are imbedded between eastern regimes (shadow type) with westward-propagating perturbations and western regimes with eastward-advected Rossby waves. Meridional northward propagation is allowed in this window north of the zero wind curl line. Remarkably, the mean zero curl line lies along $50^{\circ} \mathrm{S}$, that is, just north of the ACC. Therefore, the northward diversion of the ACC at the surface east of the East Pacific Rise (EPR) (Fig. 4), finally joining the zonally elongated West Drift, could be the invasion of the southern gyre (here the ACC) across the zero wind stress curl line in the surface field, as depicted in Schopp and Arhan (1986). Additionally, the presence of a dynamical window locally altering the stratification could also explain the PV minimum and the very weak PV meridional gradient (Chen and Dewar 1993). Bottom topography, instead, controls the diversion occurring at the EPR. The northward diversion of the ACC is then due to a combination of the two mechanisms.

Last, the exchange-window scenario implies the existence of an eastward surface flow, allowing it to stop or to reverse the second-baroclinic-mode Rossby 


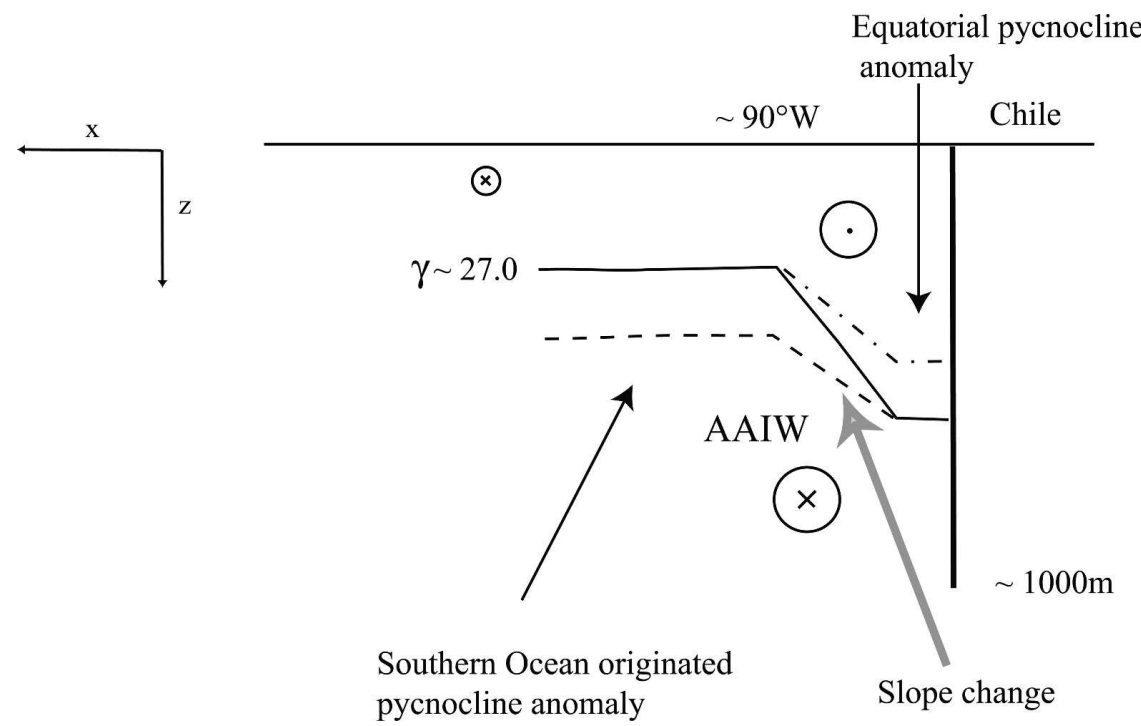

FIG. 10. Sketch on the vertical plane of examples of the mechanisms that can affect the AAIW transport at $\sim 43^{\circ} \mathrm{S}$. The 27.0 neutral surface is considered here as the interface between the AAIW and the upper layers. The slope of the interface (indicated by the gray arrow) is associated with the baroclinic current system and thus the AAIW export. Dashed line represents the interface in case of a deepening of the Southern Ocean pycnocline, which propagated northward through the exchange window. Dotted-dashed line represents the interface in presence of an equatorial-originated rise of the pycnocline along the coast. Both mechanisms can produce a change in the slope of the interface and then in the AAIW export. The change in the slope (and the consequent transport anomaly) is observed along the whole western boundary of the eastern regime (green line in Figs. 8a,b; see also Hirst and Godfrey 1993).

wave propagation (Schopp and Arhan 1986). In fact, an eastward surface flow of ACC origin is observed at the surface between $55^{\circ}$ and $40^{\circ} \mathrm{S}$ (Fig. 4). Furthermore, Killworth and Blundell (2003a) recently presented global estimates for the baroclinic Rossby wave propagation, including the effect of topographic slope and mean velocity field. Their results support the scenario proposed here. First, both first and second baroclinic modes have an absolute zonal minimum in the zonal wave speed between $53^{\circ}$ and $43^{\circ} \mathrm{S}, 120^{\circ} \mathrm{W}$ and the coast with a discontinuity at $100^{\circ} \mathrm{W}$ in both fields [see figures in Killworth and Blundell (2003a) to appraise how striking this anomaly is with respect to mean values at the same latitude]. More significantly, the minimum associated with the second baroclinic mode is actually related to the interaction with a mean zonal eastward flow, while a marked topographic effect concerns the first-mode minimum (not shown; P. Killworth and J. Blundell 2004, personal communication).

\section{b. The AAIW export mechanism as part of an oceanic teleconnection?}

The AAIW injection into the southeast Pacific is ruled by local baroclinic dynamics. The model sensitiv- ity studies discussed above showed that the local baroclinic perturbations are actually only the local expression of large-scale perturbations. For instance, the anomaly of the local zonal isopycnal slope observed in the NOINDO experiment was due to a change of depth of the pycnocline to the east of the current core, with a perturbation signal originating at the Indonesian straits closure, having propagated clockwise around the basin and radiated westward from the eastern boundary. The horizontal pressure gradient associated with the pycnocline slope has been shown to be sensitive as well to a change of the pycnocline depth south or west of the area of interest, that is, by a change in the vertical structure of the ACC. This corresponds to vertically displacing the isopycnals to the west of the meridional front and producing a perturbation of the horizontal gradient as large as the one produced by the equatorial NOINDO case (see sketch in Fig. 10). In this case the perturbation cannot come from the southern tip of the American continent because coastal Kelvin waves are constrained to propagate poleward along eastern boundaries. West of this region there is the meridional PV window discussed in the previous section (Figs. 3d and $7 \mathrm{~d})$. Considering that the intermediate flow is di- 


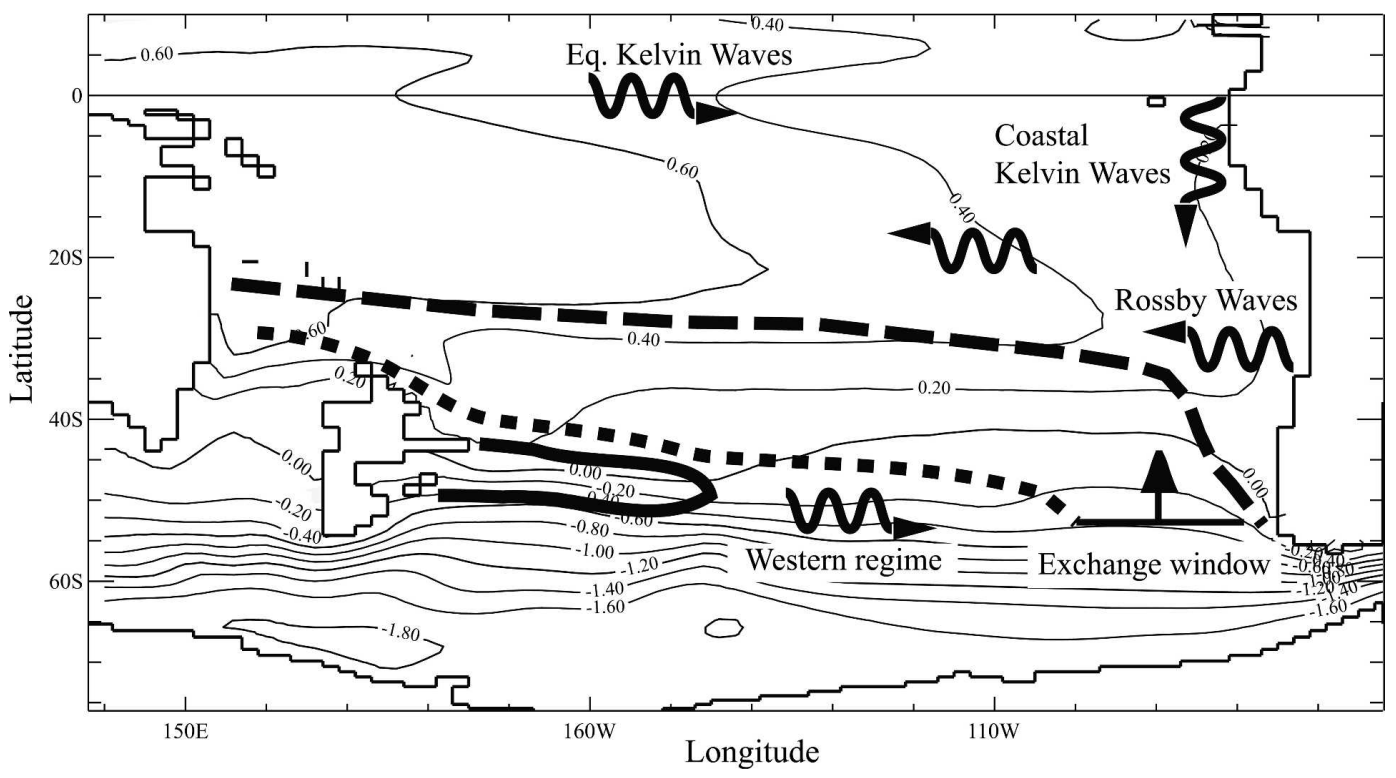

FIG. 11. Sketch on the horizontal plane of the mechanisms that can affect the AAIW export superimposed on the model mean SSH (m) and the model 1000-m isobath. Meandering arrows indicate the possible wave propagations, which are responsible for the mapping of remote pycnocline anomalies onto the southeast Pacific. The eastern boundary of the western regime is indicated by the dotted line. Notably, it bounds the deep core of the subtropical gyre (thick black line). The dashed-dotted line represents the boundary of the eastern regime, which coincides with the region of sensitivity of the slope of the interface (i.e., the AAIW transport) to remote changes in the pycnocline depth (see text and Fig. 10). The region between the two lines can be affected by the northward propagation of anomalies from the Southern Ocean through the exchange window (indicate by a straight arrow). The coastal region can be affected by anomalies originated at the equator.

rected northward, one could speculate that the ACC sets the meridionally constant $\mathrm{PV}$ value. The $\mathrm{PV}$ is, in fact, locally related to the vertical separation of isopycnals; therefore, a change of the isopycnal depth in the ACC (e.g., in GM2 and SWIND2) would alter the AAIW potential vorticity along the subpolar front. The $\mathrm{PV}$ (or stratification) perturbation is propagated northward through the dynamical window, altering the pycnocline depth north of $55^{\circ} \mathrm{S}$ and changing, eventually, the zonal slope of the flow/underflow isopycnal interface. This would accelerate or decelerate the AAIW main flow, exactly as it occurs in the case in which the perturbation is applied in the equatorial region (NOINDO).

In summary, the equatorward penetration of AAIW appears to be located exactly at the junction of the Rossby western and eastern regimes (see sketch in Fig. 11). The strength of the wind-forced mean current advects waves either eastward west of this window or westward east of it. The strength of this front at the junction can therefore be affected either by perturbations originating in the equatorial region via the eastern regime or by Southern Ocean perturbations via the western regime (e.g., Hughes 1996). A third regime could also be a locally forced ventilation-type pertur- bation along the zero wind curl line inside the window: a regime able to radiate signals to the north into the subtropical gyre and to the south into the ACC. This latter regime has been excluded because ventilation does not seem to occur along the zero wind stress curl line. The AAIW export is ruled by the large-scale meridional pressure gradient between the ACC and the equator, projected into a local zonal baroclinic shear via planetary wave propagation. It can be expected that remote baroclinic forcing can change the current characteristics via wave propagations, that is, the AAIW export into the Pacific. The wave mechanism is, in fact, very rapid and is able to affect remote regions on short time scales (even ENSO-like: e.g., Hormazabal et al. 2001, 2002; Vega et al. 2003;). Recently, the existence of remote oceanic teleconnections in the thermohaline circulation due to planetary wave (first baroclinic mode) propagation has been proposed (e.g., Cessi et al. 2004; Huang et al. 2000). Here we do not address these variability issues, but on the basis of previous considerations we can speculate that the mechanism for the control of the interbasin exchange at intermediate depths (via the second baroclinic mode) proposed here is an extension of the type of teleconnected mechanism proposed in these studies. For instance, the ACC den- 
sity structure can be altered by changes occurring in the North Atlantic Deep Water formation region, as discussed by, for example, Goodman (2001); compare their distribution of the anomaly of the pycnocline depth in the South Pacific with our Fig. 8b.

\section{Conclusions}

In this study, NODC data have been used in conjunction with output from an ocean circulation model to address the ventilation pathways and dynamical controls on the injection of AAIW into the South Pacific. The analysis allowed for a better identification of a pathway for the renewal of Pacific AAIW, with that pathway consisting of a northward flow in the southwestern South Pacific. This has been shown to be consistent with tracer distributions on a neutral surface corresponding to AAIW. Concerning the ventilation source of this AAIW, this study did not reveal any clear evidence of a local origin for AAIW, although owing to data sparcity a local ventilation source cannot be excluded. A more complete study on the formation mechanisms is, in any case, necessary to address the issue.

In terms of its dynamics, the weak meridional gradient in potential vorticity associated with AAIW export has been interpreted here as being due to the existence of a dynamical exchange window where Rossby waves carry perturbation signals northward around the South Pacific subtropical gyre, connecting the ACC with the subtropics. This scenario is supported by the existence of a local minimum in the Rossby wave zonal speed observed in previous in situ data analyses (Killworth and Blundell 2003a,b). Furthermore, we speculated that, because of the vanishing meridional Sverdup transport, most of the AAIW export should occur as part of a strictly baroclinic current structure.

The main features of the AAIW export, together with observed PV fields, have been well reproduced by a global ocean model. Another important result is that the modeling experiments clearly indicate that the large-scale baroclinic current structure west of the Chilean coast is driven by the basin-scale meridional pressure gradient field. In other words, this study clearly shows the existence of a remote connection mechanism between the Tropics and the Southern Ocean-a purely oceanic mechanism. Similar remote connections mechanisms have been recently proposed to explain the variability of the upper thermohaline circulation, but, importantly, here we have shown its importance for the intermediate circulation. The SAMW is supposed to be exported by subduction along the subantarctic front (Hanawa and Talley 2001). Another consequence of this study is thus that SAMW and AAIW appear to be ruled by a different export mechanism. Although this study was performed with climatological forcing, it will be left for further investigation to evaluate how these potentially decoupled circulation features vary in their respective transports. Additionally, care should be taken when analyzing data or model results in trying to identify a global warming signal in the ocean.

The AAIW exports freshwater and nutrients toward the Tropics and the equator. If at least part of its export is driven by the equatorial variability, as proposed here, it can represent a possible feedback on the equatorial/ tropical physical and biological dynamics (e.g., Dugdale et al. 2002; Sarmiento et al. 2004). By being also controlled by the Southern Ocean, on the other hand, it can represent a remote forcing to the equatorial dynamics. Last, even if their lower latitudes do not allow for a direct connection between the Southern Ocean and the Tropics, the mechanism proposed here for the interbasin exchange could also be at work in other eastern regions such as Africa or Australia. This could be the case, for instance, for AAIW injection into the North Atlantic basin where it forms the return branch of the basin thermohaline circulation, which recently has been associated with the intermediate flow observed just to the east of South Africa (e.g., Schmid et al. 2001).

Acknowledgments. We acknowledge the National Oceanographic Data Center as well as the CERSAT data center for making their rich databases publicly available. Peter Killworth and Jeff Blundell kindly allowed us to access their estimates of Rossby wave speeds. Clement de Boyer Montégut provided us with the climatology of the mixed layer depths, and Sophie Cravatte gave us access to postprocessed ARGO data. The producers of the ODV software are also acknowledged, as well as D.R. Jackett and T. McDougall for their software for the neutral density computation.

The authors gratefully acknowledge discussions with Michel Arhan, who suggested that we consider the existence of an exchange window, and Lynne Talley, for interesting discussions and whose seminal papers on AAIW were the inspirations for this research. Discussions with Peter Killworth, Michael S. McCartney, Ettore Salusti, Sabrina Speich, Anne Marie Treguier, and Maurizio Ribera D'Alcalà are also kindly acknowledged. The several scientific discussions with B. Linné were also very fruitful.

This research was part of the French BILBO project supported by the Programme National d'Etude du Climat (PNEDC). Computational time was provided by the Institut du Développement et des Ressources en 
Informatique Numérique (IDRIS). A contribution from the Italian PNRA (Project CANOPO) is also acknowledged.

\section{REFERENCES}

Blanke, B., and S. Raynaud, 1997: Kinematics of the Pacific Equatorial Undercurrent: An Eulerian and Lagrangian approach from GCM results. J. Phys. Oceanogr., 27, 1038-1053.

Borowski, D., R. Gerdes, and D. Olbers, 2002: Thermohaline and wind forcing of a circumpolar channel with blocked geostrophic contours. J. Phys. Oceanogr., 32, 2520-2540.

Brzezinski, M. A., M.-L. Dickson, D. M. Nelson, and R. Sambrotto, 2003: Ratios of $\mathrm{Si}, \mathrm{C}$ and $\mathrm{N}$ uptake by microplankton in the Southern Ocean. Deep-Sea Res. II, 50, 619-633.

Cessi, P., K. Bryan, and R. Zhang, 2004: Global seiching of thermocline waters between the Atlantic and the Indian-Pacific Ocean Basins. Geophys. Res. Lett., 31, L04302, doi:10.1029/ 2003 GL019091.

Chaigneau, A., and O. Pizarro, 2005: Mean surface circulation and mesoscale turbulent flow characteristics in the eastern South Pacific, from satellite tracked drifters. J. Geophys. Res., 110, C05014, doi:10.1029/2004JC002628.

Chen, L. G., and W. K. Dewar, 1993: Intergyre communication in a three-layer model. J. Phys. Oceanogr., 23, 855-878.

Conkright, M. E., and Coauthors, 2002: Introduction. Vol. 1, World Ocean Database 2001, NOAA Atlas NESDIS 42, 160 pp.

Cunningham, S. A., S. G. Alderson, B. A. King, and M. A. Brandon, 2003: Transport and variability of the Antarctic Circumpolar Current in Drake Passage. J. Geophys. Res., 108, 8084, doi:10.1029/2001JC001147.

Davis, R. E., 1998: Preliminary results from directly measuring mid-depth circulation in the tropical and south Pacific. $J$. Geophys. Res., 103, 24 619-24 639.

_ 2005: Intermediate-depth circulation of the Indian and South Pacific Oceans measured by autonomous floats. $J$. Phys. Oceanogr., 35, 683-707.

de Boyer Montégut, C., G. Madec, A. S. Fischer, A. Lazar, and D. Iudicone, 2004: Mixed layer depth over the global ocean: An examination of profile data and a profile-based climatology. J. Geophys. Res., 109, C12003, doi:10.1029/2004JC002378.

Dugdale, R. C., A. G. Wischmeyer, F. P. Wilkerson, R. T. Barber, F. Chai, M. Jiang, and T.-H. Peng, 2002: Meridional asymmetry of source nutrients to the equatorial Pacific upwelling ecosystem and its potential impact on ocean-atmosphere $\mathrm{CO}_{2}$ flux; A data and modeling approach. Deep-Sea Res. II, 49, 2513-2533.

Dutay, J.-C., and Coauthors, 2002: Evaluation of ocean model ventilation with CFC-11: Comparison of 13 global ocean models. Ocean Modell., 4, 89-120.

England, M. H., J. S. Godfrey, A. C. Hirst, and M. Tomczak, 1993: The mechanism for Antarctic Intermediate Water renewal in a world ocean model. J. Phys. Oceanogr., 23, 1553-1560.

Fichefet, T., and M. A. Morales Maqueda, 1997: Sensitivity of a global sea ice model to the treatment of ice thermodynamics and dynamics. J. Geophys. Res., 102, 609-646.

Fine, R. A., K. A. Maillet, K. S. Sullivan, and D. Willey, 2001: Circulation and ventilation flux of the Pacific Ocean. J. Geophys. Res., 106, 22 159-22 178.

Gent, P. R., and J. C. McWilliams, 1990: Isopycnal mixing in ocean circulation models. J. Phys. Oceanogr., 20, 150-155.
Gnanadesikan, A., 1999: A simple predictive model for the structure of the oceanic pycnocline. Science, 283, 2077-2079.

Goodman, P. J., 2001: Thermohaline adjustment and advection in an OGCM. J. Phys. Oceanogr., 31, 1477-1497.

Hanawa, K., and L. D. Talley, 2001: Mode waters. Ocean Circulation and Climate, G. Siedler and J. Church, Eds., International Geophysics Series, Vol. 77, Academic Press, 373-386.

Haynes, P. H., 1985: Wind gyres in circumpolar oceans. J. Phys. Oceanogr., 15, 670-683.

Hirst, A. C., and J. S. Godfrey, 1993: The role of Indonesian throughflow in a global ocean GCM. J. Phys. Oceanogr., 23, 1057-1086.

_ , and -1994 : The response to a sudden change in Indonesian throughflow in a global ocean GCM. J. Phys. Oceanogr., 24, 1895-1910.

Hormazabal, S., G. Shaffer, J. Letelier, and O. Ulloa, 2001: Local and remote forcing of sea surface temperature in the coastal upwelling system off Chile. J. Geophys. Res., 106, $16657-$ 16672 .

-,- , and O. Pizarro, 2002: Tropical Pacific control of intraseasonal oscillations off Chile by way of oceanic and atmospheric pathways. Geophys. Res. Lett., 29, 1081, doi:10.1029/2001GL013481.

Huang, R. X., and B. Qiu, 1998: The structure of the wind-driven circulation in the subtropical South Pacific Ocean. J. Phys. Oceanogr., 28, 1173-1186.

_- M. Cane, N. Naik, and P. J. Goodman, 2000: Global adjustment of the thermocline in response to deep water formation. Geophys. Res. Lett., 27, 759-762.

Hughes, C. W., 1996: The Antarctic circumpolar current as a waveguide for Rossby waves. J. Phys. Oceanogr., 26, 13751387.

Jackett, D. R., and T. J. McDougall, 1997: A neutral density variable for the world's oceans. J. Phys. Oceanogr., 27, 237-263.

Karsten, R., H. Jones, and J. Marshall, 2002: The role of eddy transfer in setting the stratification and transport of a Circumpolar Current. J. Phys. Oceanogr., 32, 39-54.

Karstensen, J., 2004: Formation of the South Pacific shallow salinity minimum: A Southern Ocean pathway to the tropical Pacific. J. Phys. Oceanogr., 34, 2398-2412.

Killworth, P. D., and J. R. Blundell, 2003a: Long extratropical planetary wave propagation in the presence of slowly varying mean flow and bottom topography. Part I: The local problem. J. Phys. Oceanogr., 33, 784-801.

—, and — 2003b: Long extratropical planetary wave propagation in the presence of slowly varying mean flow and bottom topography. Part II: Ray propagation and comparison with observations. J. Phys. Oceanogr., 33, 802-821.

Luyten, J., and H. Stommel, 1986: Gyres driven by combined wind and buoyancy flux. J. Phys. Oceanogr., 16, 1551-1560.

— J. Pedlosky, and H. Stommel, 1983: The ventilated thermocline. J. Phys. Oceanogr., 13, 292-309.

Madec, G., P. Delecluse, M. Imbard, and C. Lévy, 1998: OPA 8.1 Ocean General Circulation Model reference manual. Institut Pierre-Simon Laplace Note du Pôle de Modélisation No. 11, $91 \mathrm{pp}$.

Marshall, J., and T. Radko, 2003: Residual mean solutions for the Antarctic Circumpolar Current and its associated overturning circulation. J. Phys. Oceanogr., 33, 2341-2354.

McCartney, M. S., 1977: Subantarctic Mode Water. A Voyage of Discovery: George Deacon 70th Anniversary Volume, M. V. Angel, Ed., Pergamon, 103-119. 
— 1982 : The subtropical recirculation of mode waters. J. Mar. Res., 40 (Suppl.), 427-464.

McDougall, T. J., 1987: Neutral surfaces. J. Phys. Oceanogr., 17, 1950-1964.

Nuñez, R., and R. Rojas, 1998: Circulation offshore Southern Chile, PR14 Repeated Hydrography Section. International WOCE Newsletter, Vol. 32, WOCE International Project Office, Southampton, United Kingdom, 40-42.

Pedlosky, J., 1998: Ocean Circulation Theory. Springer-Verlag, $453 \mathrm{pp}$.

Piola, A. R., and A. L. Georgi, 1982: Circumpolar properties of Antarctic Intermediate Water and Subantarctic Mode Water. Deep-Sea Res., 29, 687-711.

Reid, J. L., 1986: On the total geostrophic circulation of the South Pacific Ocean: Flow patterns, tracers and transports. Progress in Oceanography, Vol. 16, Pergamon, 1-61.

_ 1997: On the total geostrophic circulation of the Pacific Ocean: Flow patterns, tracers, and transports. Progress in Oceanography, Vol. 39, Pergamon, 263-352.

Rhines, P. B., and W. R. Young, 1982a: Homogenization of potential vorticity in planetary gyres. J. Fluid Mech., 122, 347367.

- and - 1982b: A theory of the wind-driven circulation. I. Midocean gyres. J. Mar. Res., 40 (Suppl.), 559-596.

Rojas, R., N. Silva, W. Garcia, and Y. Guerriero, 1995: WHP repeated hydrography section PR14, offshore southern Chile. International WOCE Newsletter, WOCE International Project Office, Southampton, United Kingdom, Vol. 20, 31-33.

Russell, J. L., and A. G. Dickson, 2003: Variability in oxygen and nutrients in South Pacific Antarctic Intermediate Water. Global Biogeochem. Cycles, 17, 1033, doi:10.1029/ $2000 \mathrm{~GB} 001317$.

Saenko, O., A. J. Weaver, and M. H. England, 2003: A region of enhanced northward Antarctic Intermediate Water transport in a coupled climate model. J. Phys. Oceanogr., 33, 15281535 .

Sarmiento, J. L., N. Gruber, M. Brzezinksi, and J. Dunne, 2004: High latitude controls of thermocline nutrients and low latitude biological productivity. Nature, 426, 56-60.

Schlitzer, R., cited 2004: Ocean data view. Alfred Wegener Institut. [Available online at http:/www.awi-bremerhaven.de/ GEO/ODV.]

Schmid, C., R. L. Molinari, and S. L. Garzoli, 2001: New observation of the intermediate depth circulation in the tropical Atlantic. J. Mar. Res., 59, 281-312.

Schneider, W., R. Fuenzalida, E. Rodríguez-Rubio, J. GarcésVargas, and L. Bravo, 2003: Characteristics and formation of Eastern South Pacific Intermediate Water. Geophys. Res. Lett., 30, 1581, doi:10.1029/2003GL017086.
Schopp, R., 1988: Spin up toward communication between oceanic subpolar and subtropical gyres. J. Phys. Oceanogr., 18, 1241-1259.

— model for the eastern North Atlantic. J. Phys. Oceanogr., 16, 344-357.

Shaffer, G., S. Hormazabal, O. Pizarro, and M. Ramos, 2004: Circulation and variability in the Chile Basin. Deep-Sea Res. I, 51, 1367-1386.

Sloyan, B. M., and S. R. Rintoul, 2001a: Circulation, renewal and modification of Antarctic mode and intermediate water. $J$. Phys. Oceanogr., 31, 1005-1030.

— , and 2001b: The Southern Ocean limb of the global deep overturning circulation. J. Phys. Oceanogr., 31, 143-173.

Sørensen, J. V. T., J. Ribbe, and G. Shaffer, 2001: On Antarctic Intermediate Water mass formation in ocean general circulation models. J. Phys. Oceanogr., 31, 3295-3311.

Stramma, L., R. G. Peterson, and M. Tomczak, 1995: The South Pacific Current. J. Phys. Oceanogr., 25, 77-91.

Strub, P. T., J. M. Mesias, V. Montecino, J. Rutllant, and S. Salinas, 1998: Coastal ocean circulation off western South America. The Sea, A. R. Robinson and K. H. Brink, Eds. Regional Studies and Syntheses, Vol. 11, Wiley, 273-313.

Sverdrup, H. U., M. W. Johnson, and R. H. Fleming, 1942: The Oceans: Their Physics, Chemistry and General Biology. Prentice Hall, 1087 pp.

Talley, L. D., 1996: Antarctic Intermediate Water in the South Atlantic. The South Atlantic: Present and Past Circulation, G. Wefer et al., Eds., Springer-Verlag, 219-238.

Timmermann, R., H. Goosse, G. Madec, T. Fichefet, C. Ethe, and V. Dulière, 2005: On the representation of high latitude processes in the ORCALIM global coupled sea ice-ocean model. Ocean Modell., 8, 175-201.

Toggweiler, J. R., and B. Samuels, 1998: On the ocean's largescale circulation near the limit of no vertical mixing. J. Phys. Oceanogr., 28, 1832-1852.

Tomczak, M., and J. S. Godfrey, 1994: Regional Oceanography: An Introduction. Pergamon, 422 pp.

Treguier, A. M., I. M. Held, and V. D. Larichev, 1997: On the parameterization of quasi-geostrophic eddies in primitive equation ocean models. J. Phys. Oceanogr., 27, 567-580.

Tsuchiya, M., and L. D. Talley, 1998: A Pacific hydrographic section at $88^{\circ} \mathrm{W}$ : Water property distribution. J. Geophys. Res., 103, 12 899-12 918.

Vega, A., Y. du-Penhoat, B. Dewitte, and O. Pizarro, 2003: Equatorial forcing of interannual Rossby waves in the eastern South Pacific. Geophys. Res. Lett., 30, 1197, doi:10.1029/ 2002 GL015886. 